(1) Nordregio

\title{
Enhanced Labour
}

Market Opportunities

for Immigrant

Women

- case studies from Arctic cities

Edited by Hjördis Rut Sigurjónsdóttir,

Mari Wøien and Mantrys Meckl

NORDREG Q(MANEPRT 2018:3

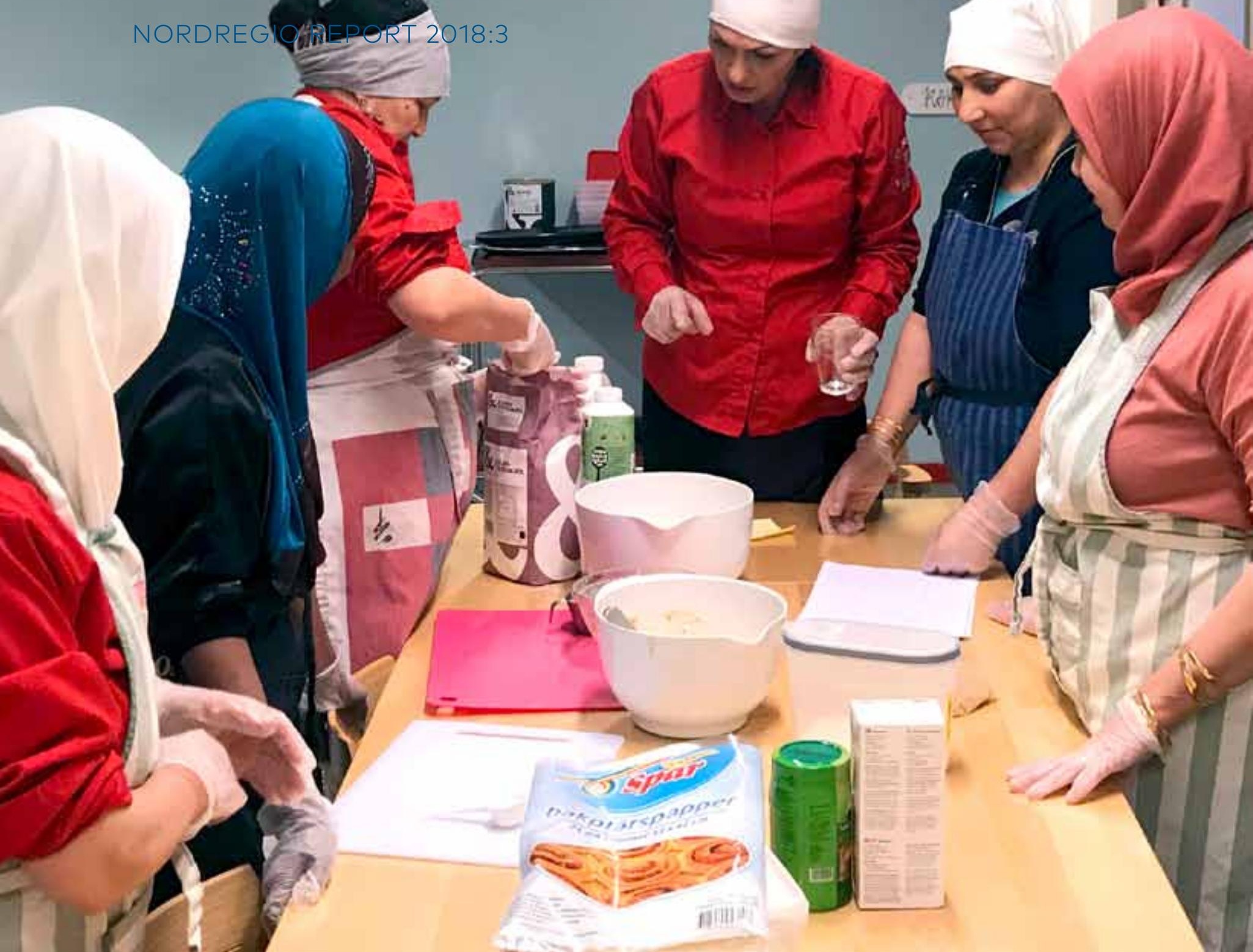





\section{Enhanced Labour}

Market Opportunities for Immigrant

\section{Women}

- case studies from Arctic cities

Authors: Hjördis Rut Sigurjónsdóttir, Mari Wøien, Markus Meckl, Stéphanie Barillé, Nafisa Yeasmin, Aija Burdikova, Timo Koivurova and Liisa Perjo

NORDREGIO REPORT 2018:3 
Enhanced Labour Market Opportunities for Immigrant Women

- Case studies from Akureyri, Luleå and Rovaniemi

Nordregio Report 2018:3

ISBN 978-91-87295-62-1

ISSN 1403-2503

DOI doi.org/10.30689/R2018:3.1403.2503

(c) Nordregio 2018

Nordregio

P.O. Box 1658

SE-111 86 Stockholm, Sweden

nordregio@nordregio.org

www.nordregio.org

www.norden.org

Editors: Hjördis Rut Sigurjónsdóttir, Mari Wøien and Markus Meckl

Cover photo: Hjördis Rut Sigurjónsdóttir

Layout: Elín Esther Magnúsdóttir

\section{Nordregio}

is a leading Nordic and European research centre for regional development and planning, established by the Nordic Council of Ministers in 1997. We conduct solution-oriented and applied research, addressing current issues from both a research perspective and the viewpoint of policymakers and practitioners. Operating at the international, national, regional and local levels, Nordregio's research covers a wide geographic scope, with an emphasis on the Nordic and Baltic Sea Regions, Europe and the Arctic.

\section{The Nordic co-operation}

Nordic co-operation is one of the world's most extensive forms of regional collaboration, involving Denmark, Finland, Iceland, Norway, Sweden, and the Faroe Islands, Greenland, and Åland. Nordic co-operation has firm traditions in politics, the economy, and culture. It plays an important role in European and international collaboration, and aims at creating a strong Nordic community in a strong Europe. Nordic co-operation seeks to safeguard Nordic and regional interests and principles in the global community. Common Nordic values help the region solidify its position as one of the world's most innovative and competitive.

\section{The Nordic Council of Ministers}

is a forum of co-operation between the Nordic governments. The Nordic Council of Ministers implements Nordic co-operation. The prime ministers have the overall responsibility. Its activities are co-ordinated by the Nordic ministers for co-operation, the Nordic Committee for co-operation and portfolio ministers. Founded in 1971.

\section{The Nordic Council}

is a forum for co-operation between the Nordic parliaments and governments. The Council consists of 87 parliamentarians from the Nordic countries. The Nordic Council takes policy initiative s and monitors Nordic co-operation. Founded in 1952. 


\section{Contents}

Preface

\section{Icelandic case study: Overcoming the underemployment} of immigrant women in Akureyri

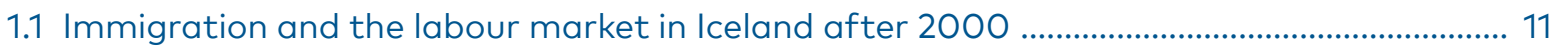

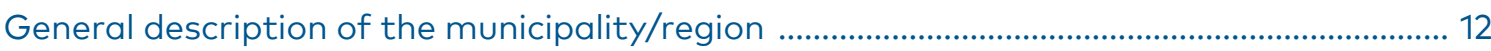

1.2 The relationship between language knowledge and the labour market ............................... 12

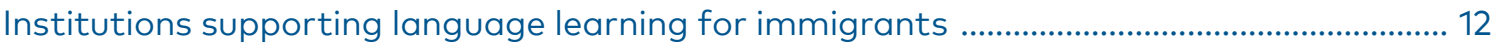

Language as a pre-requisite for adequate employment ...................................................... 13

1.3 The integration in the labour market through internships .................................................... 14

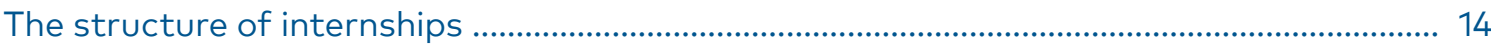

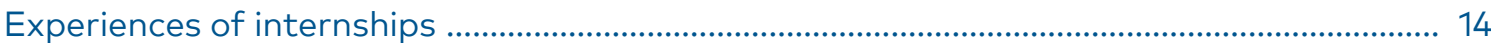

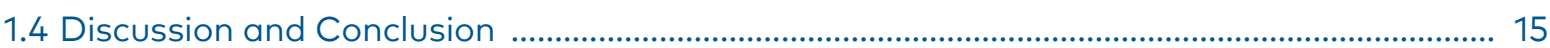

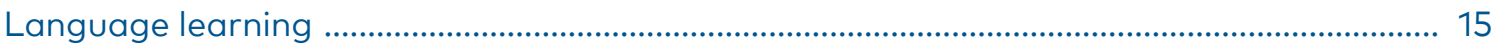

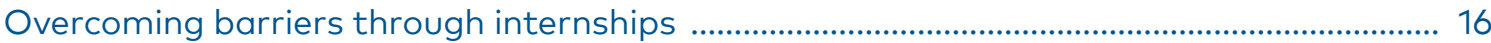

\section{Swedish case study: Labour market integration} of immigrant women in Luleå, Sweden .............................................................................. 19

2.1 Labour market integration of Immigrants in Sweden and Luleå ........................................... 19

Tools and challenges for labour market integration ............................................................... 20

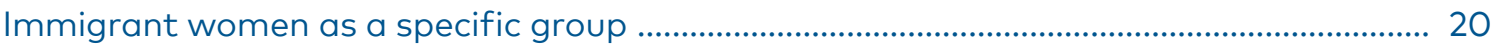

Labour market integration policy and governance in Luleå ................................................... 21

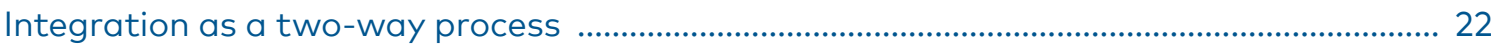

2.2 Analysis of the labour market measure: Korta Vägen ............................................................. 23

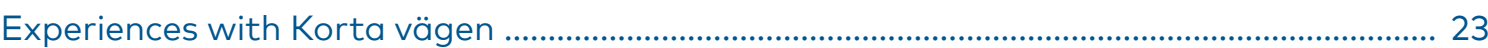

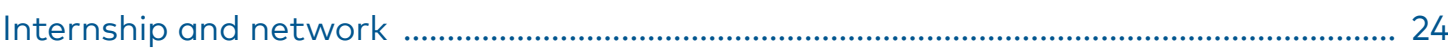

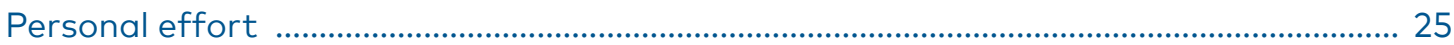

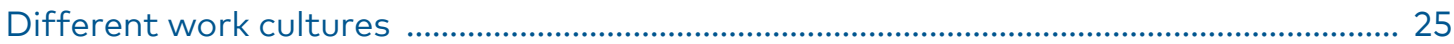

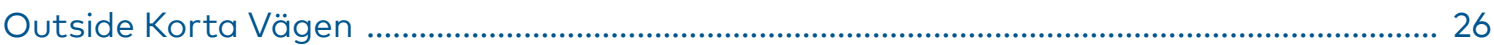

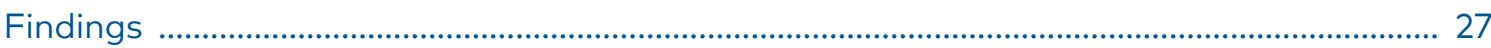

2.3 Analysis of Labour Market Measures: Bazar ............................................................................... 27

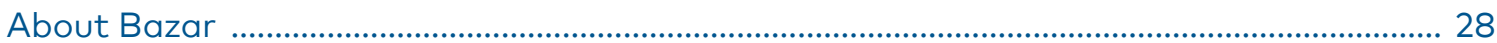

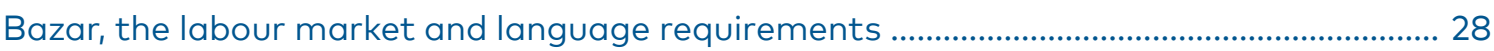

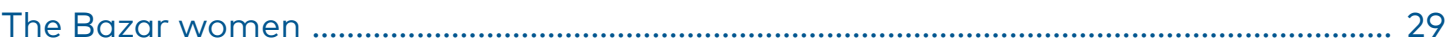

Creating Social Networks: Women and work ...................................................................... 30

The role of culture, tradition and a female community ....................................................... 31

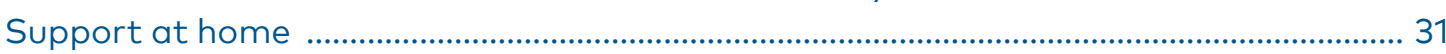




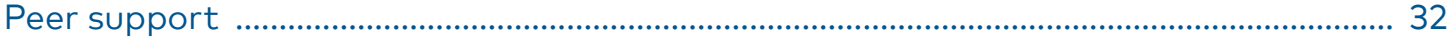

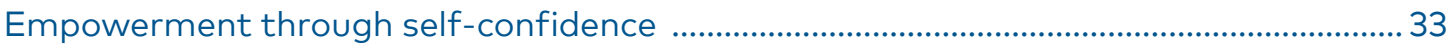

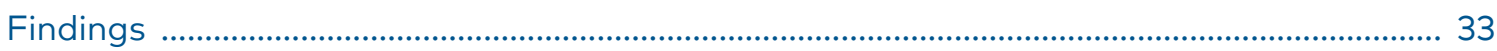

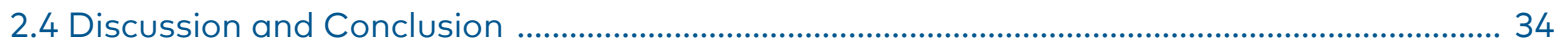

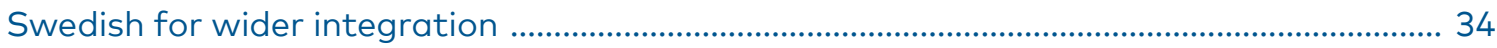

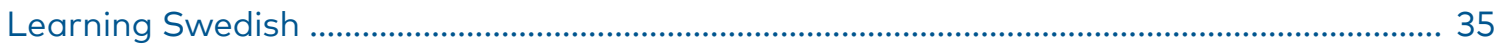

The Programme Factor: Empowerment and Social Networks ............................................... 35

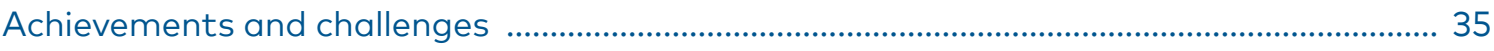

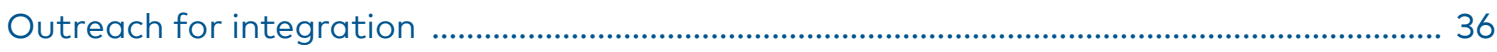

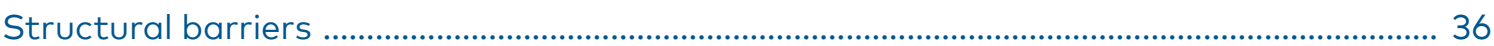

\section{Finnish case study: Enhancing labour market opportunity} for immigrant women in Finnish Lapland ....................................................................... 39

3.1 Immigration and the labour market in Finland after 2000 ................................................... 39

3.2 The relationship between language knowledge and the labour market ................................ 41

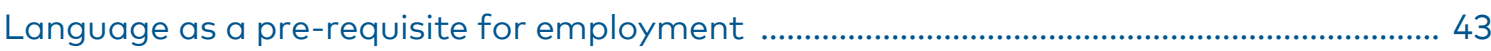

3.3 The integration in the labour market through internships ...................................................... 44

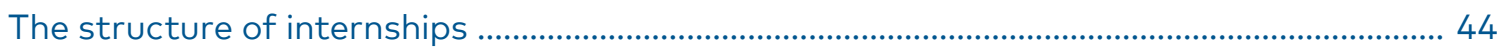

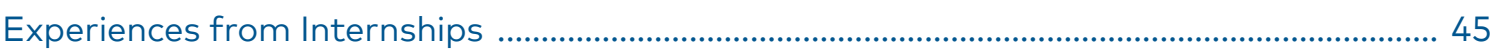

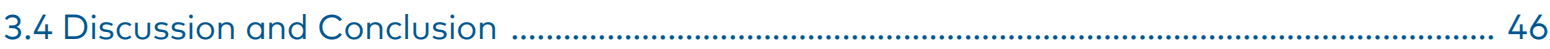

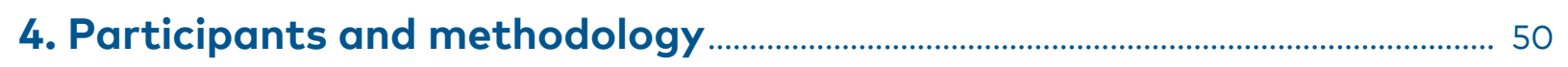

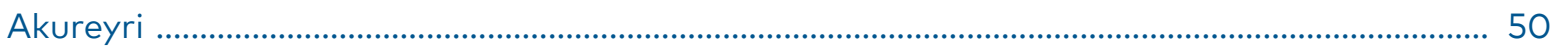

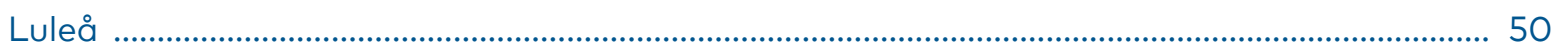

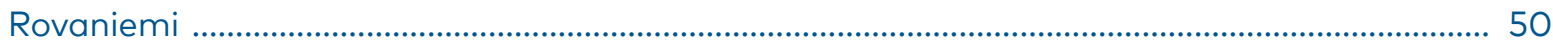

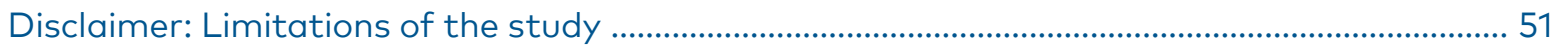

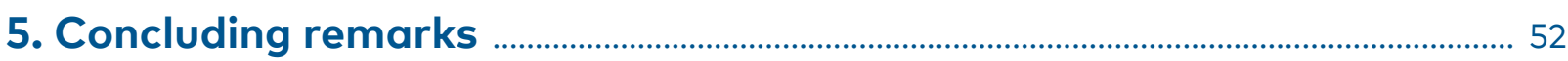

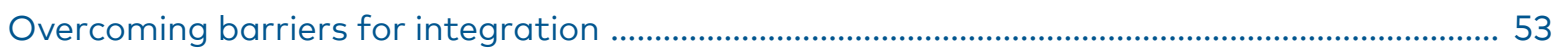

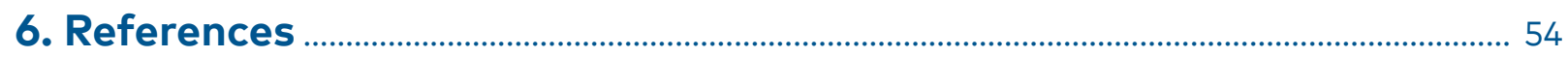

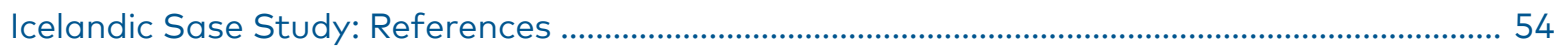

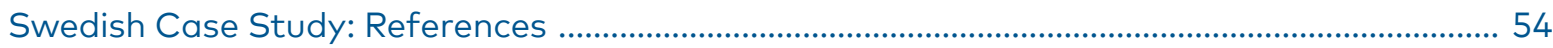

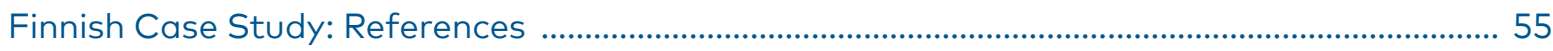




\section{Preface}

This publication is the outcome of a comparative study focusing on immigrant women's access to the labour market in small and medium-sized cities in the Arctic region. The study is funded by the Nordic Gender Equality Fund, which supports projects aimed at knowledge sharing and problem solving with regards to gender equality across the Nordic countries. The research was carried out by the University of Akureyri, Nordregio and the University of Lapland.

The project was to investigate policies and applied practices in three small and medium-sized cities in the Nordic countries: Akureyri in Iceland, Luleå in Sweden and Rovaniemi in Finland. The objective was to identify and share best practices for improving labour market integration among immigrant women. The project also sought to examine how private and public actors may improve the opportunities in the labour market for immigrant women, as well as to give these women a voice through in-depth interviews about their labour market integration experiences in the abovementioned Nordic Arctic cities.
The case studies figuring in this publication are to be taken as a first explorative enquiry into the varied local circumstances regarding labour market integration and practices. The case studies and the desktop research form the basis for this publication. The University of Akureyri conducted the case study in Akureyri, Nordregio in Lulea and the University of Lapland in Rovaniemi. The interviews for the case studies were carried out between September and December 2017. Subsequently, the material from each case study was analysed with desktop material, articles and documents on different language and labour market measures. It is important to keep in mind that this area of research is highly dynamic, and the different initiatives in place are subject to change due to e.g. political change.

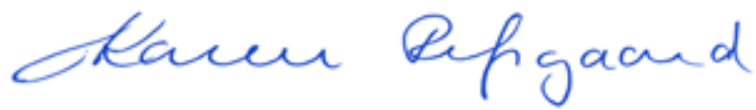

Stockholm, 3rd December 2018

Karen Refsgaard 


\section{Introduction}

Migration has been a major source of population increase in the Nordic countries for the past decades, which is particularly evident when considering the large inflows of refugees and asylum seekers in 2015, substantially contributing to this increase (Heleniak, 2018; Harbo et al., 2017). Meanwhile, the employment gap between refugees and immigrants, on the one hand, and the native-born population on the other has increased, a challenge highlighted in numerous studies in recent years (Karlsdottir et al., 2017). Moreover, despite being one of the most gender-equal regions in the world, immigrant women's marginalisation in the labour market remains a challenge to be overcome in the Nordic region.

Studies and statistic show that immigrants are one of the most vulnerable groups in the labour market in the countries at hand, and foreignborn women tend to face greater challenges in securing a job than their male counterparts. The employment rates tend to be lower amongst immigrant women, and underemployment is more common (Burdikova et al., 2018; Eurostat, 2016; Swedish Public Employment Agency, 2017a). There are many reasons for the slower labour market integration of immigrant women, but it is generally attributed to lower levels of education, family obligations and cultural differences (Karlsdottir et al., 2017). The mismatch between skills and jobs is another aspect that does not leave immigrant women untouched.

Different initiatives have been established to enhance labour market access for immigrants in the Nordic region, and some are specifically intended for women. Although there are similarities between the Nordic countries, it is not a homogeneous region in terms of labour market opportunities for immigrants, nor in terms of the proportion of immigrants in need of this access. At the same time, little research has been conducted to determine the effectiveness of the different measures in place.

This study contributes to the body of knowledge within this field by identifying policies and practises for enhancing access for immigrant

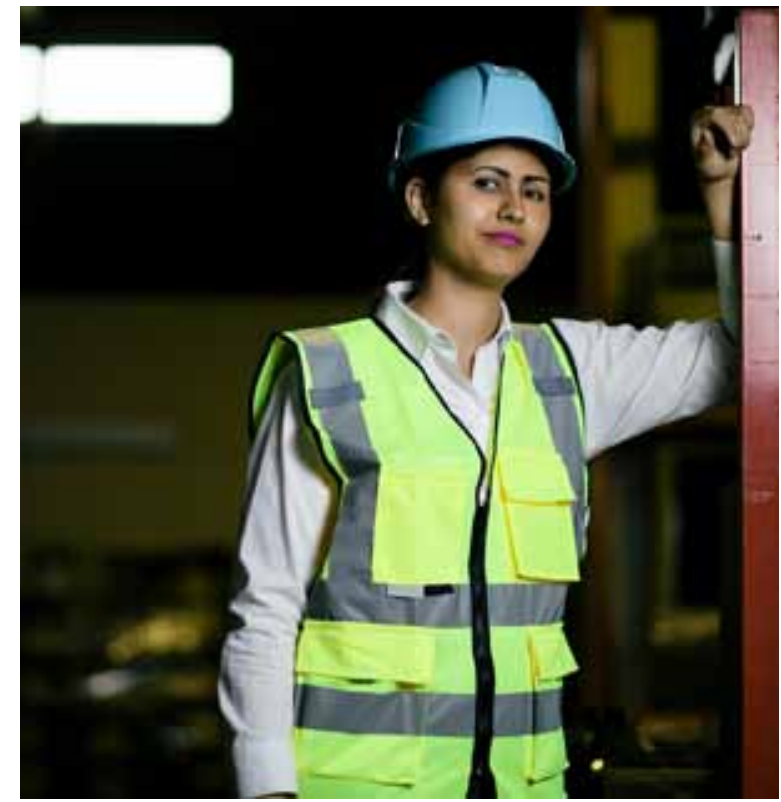

Source: Shutterstock

women to local labour markets in the Arctic region. Three small and medium-sized cities in the Nordic countries were considered in this study: Akureyri in Iceland, Luleå in Sweden and Rovaniemi in Finland. All northern cities, located by the Arctic Circle, share many of the same challenges, but vary in terms of employment rates, the number of immigrants in the cities, their integration policies and the available measures for easing the access to the labour market. The case studies comprised of in-depth interviews with actors in charge of labour market measures, as well as the women taking part in them, and was completed by relevant documents on the existing labour market measures and related research articles. A few success factors and common challenges have been identified.

The language is a major hurdle for integration, whether it is regarding labour market participation or for ensuring social inclusion. Consequently, it can make a great difference how accessible language courses are to the immigrant and how the courses are taught. This was clear throughout the case studies in this project. However, the success factors for good integration need to be measured 


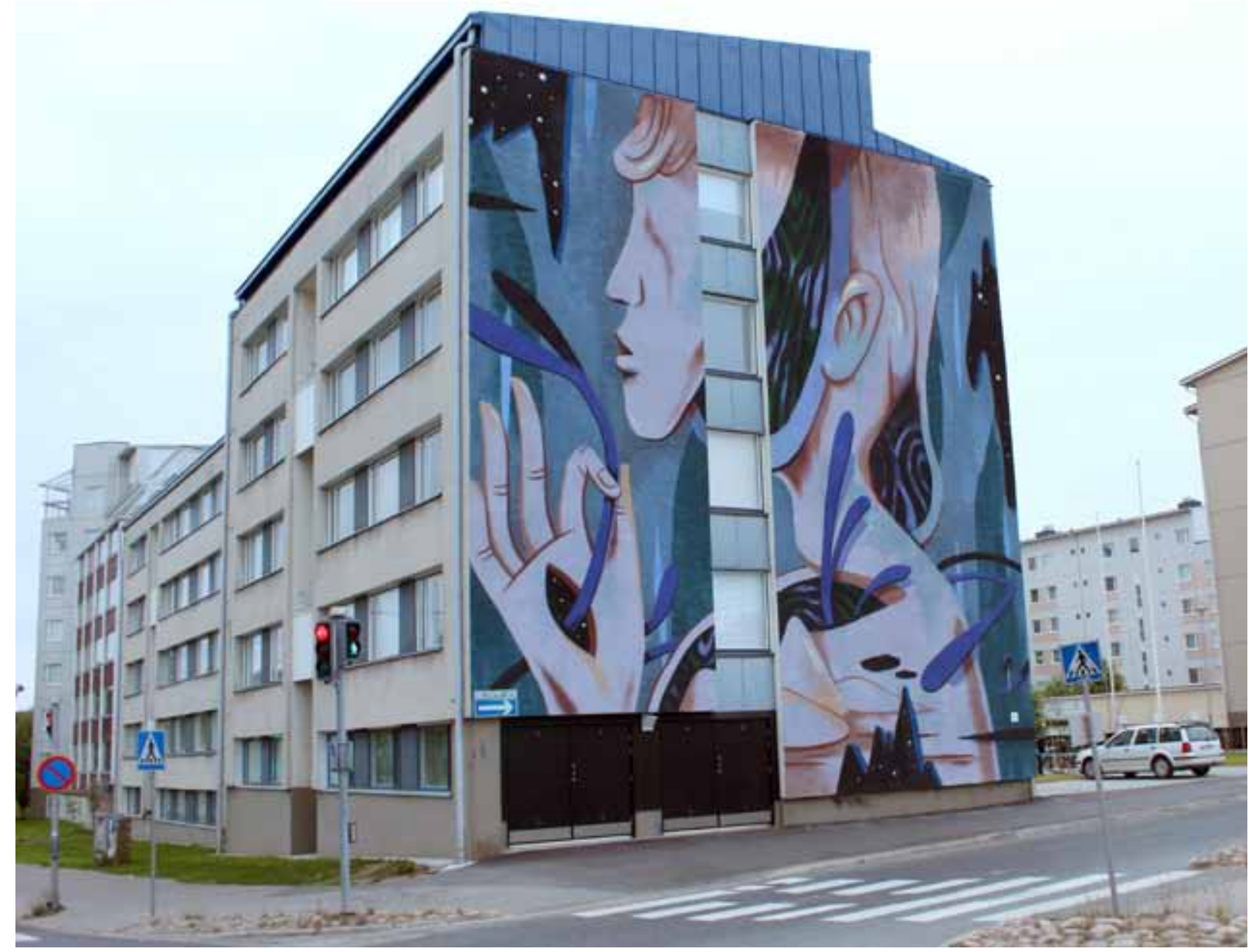

Source: Vaida Ražaitytė

more broadly. It is not always sufficient to obtain the language skills, rather there is also a need to create an understanding of the new culture and how this may complement the responsibilities and practices that are part of the immigrant's past and future. Building cultural understanding may also help the labour market integration in the long term.

It is evident that gaps need to be bridged to pave the way for successful labour market integration. Linking employers and immigrants through internships may encourage employers to hire immigrant women, all the while giving the women an opportunity to extend their social and professional networks and get a foothold in the labour market. Another important element is to provide an opportunity to complement existing competences through courses or internships to better fit the local labour market. Not having access to such support can cause immigrants to have a permanent position outside of the labour market or to get involved in employment situations not appropriate to their education, skills or backgrounds. Providing support or other appropriate measures to enter the labour market may enhance labour market opportunity for immigrant women and reduce underemployment.

This study will first present the findings from the research conducted in Akureyri. It will then go on to explore the findings from Lulea and Rovaniemi. Finally, the study will consider the similarities and differences between the case studies, alongside recommendations for policy makers. What is clear is that in this context, it is important to empower and motivate women that may feel disadvantaged, to help create opportunities for fulfilling their potential in a new country, through encouragement and the provision of real opportunities. At the same time, employers need to be encouraged to be active and provide everyone with equal opportunities: where enablers may help open doors to the local society and the co-ordination between actors and measures can play a key role. 


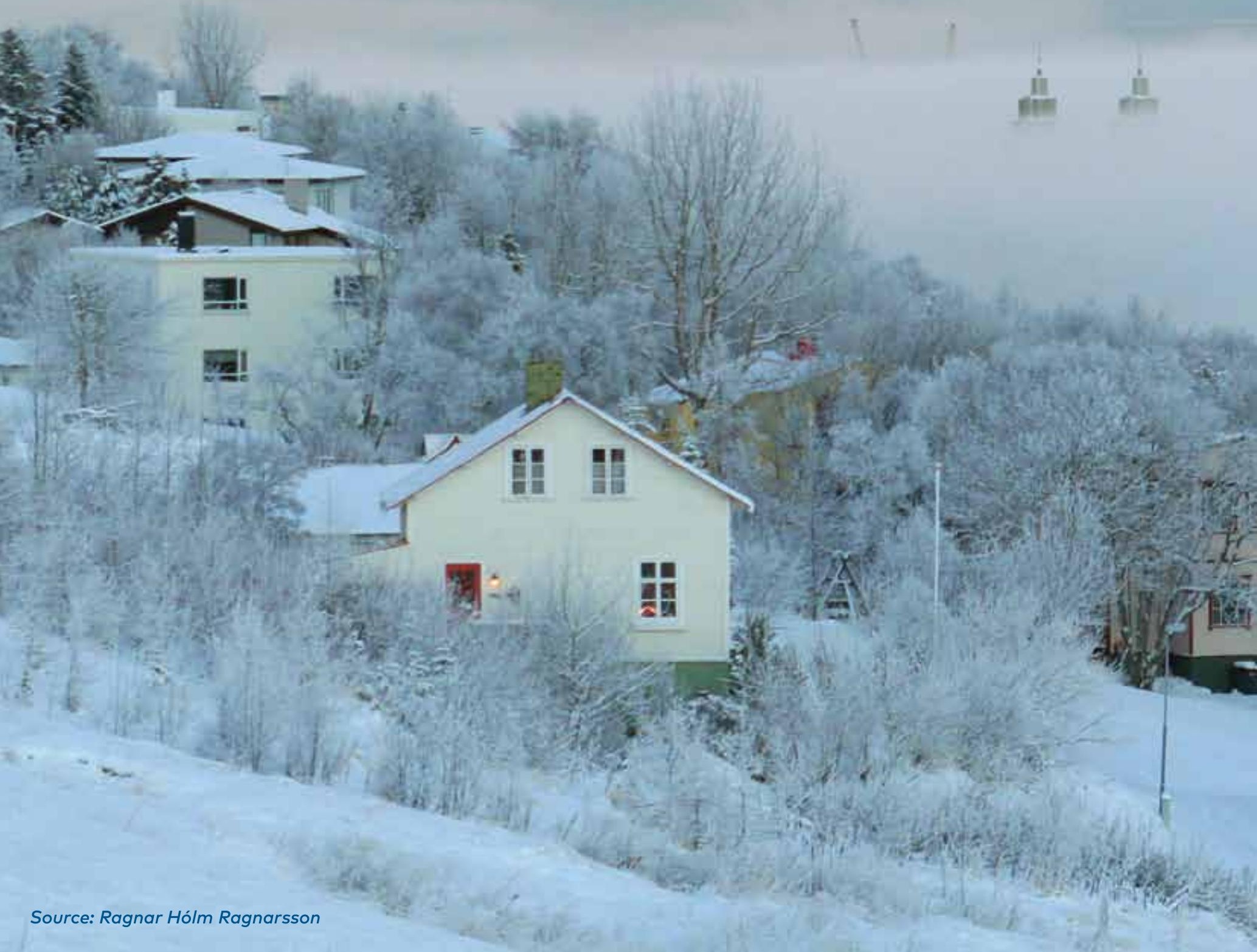




\section{Icelandic case study: Overcoming the underemployment of immigrant women in Akureyri}

Authors: Aija Burdikova, Markus Meckl and Stéphanie Barillé

\subsection{Immigration and the labour market in Iceland after $\mathbf{2 0 0 0}$}

The number of immigrants living in Iceland has been steadily on the rise for the last decade; between 2007 and 2017, the percentage of immigrants living in Iceland has increased from $6 \%$ to 8.9\%1. From 2000 onwards, increased job opportunities in construction and the opening of the labour market to citizens of the new member-states of the European Union were the main reasons behind the increase of immigrants working in Iceland. However, migrants coming to work in Iceland were not seen as active participants in the long-term economic prosperity of the country but rather as a temporary labour force. Support for the integration of immigrants by the government was scarce and a policy was introduced only in 2007 (Skaptadóttir \& Loftsdóttir, 2016), while the issue was mostly left to private initiatives.

At the peak of the Icelandic economic boom in 2008, the Directorate of Labour reported that $9 \%$ of the Icelandic workforce was composed of immigrants (Skaptadóttir, 2014). Data from 2010 shows that the immigrant unemployment rate was $14.5 \%$, which was twice as high as the rate for Icelandic citizens, as immigrants were often employed in the boom-bust sectors (ibid.). The chance of obtaining a new job after the crisis decreased for immigrants, as their previous work experience abroad was not always recognised. Before the crisis, the lack of proficiency in the local language was not considered a big issue for securing a job in Iceland, but afterwards, it proved to be an important problem. Funding for language courses became scarce (ibid.).

A survey taken among immigrants after the economic crisis showed that three-quarters of the respondents thought it would be difficult to get

1 Statistics Iceland, 2017 a job in Iceland: $71 \%$ named the lack of fluency in Icelandic as a reason, $62 \%$ assumed that employers were not eager to hire foreign workers and $41 \%$ indicated that they felt they were not well connected within Icelandic society (Wotjynska et al., 2011). A growing number of immigrants started to seek aid, and a study revealed that a third of those who received help from charities were immigrants, with a majority being unemployed individuals from Poland (Dofradóttir \& Jónsdóttir, 2010). Most of them had a lower income than the Icelanders receiving aid (ibid.), but they had more education.

Immigrants are rarely visible in regional development policy and application (Júlíusdóttir, 2010). Even though migrant workers are a growing group in all regions of Iceland, they are presented as a simple labour force, not as a source for economic prosperity (ibid.). They are absent from the discussion on entrepreneurship, despite research showing that $26 \%$ of immigrants are interested in starting their own businesses and $51 \%$ have gradvated from a university (Jónsdóttir et al., 2009). However, it is estimated that more and more immigrants are needed to fill the gap in employment in Iceland in the coming years ${ }^{2}$.

Regardless of Iceland's stereotypical portrait as a gender equality nation, the persistence of a gender-segregated labour market remains (Júlíusdóttir et al., 2013). Women have less access to the labour market, are under-represented in most companies, do not often hold management positions and earn less than their male counterparts (Jafnréttistofa, 2012); the opportunities for immigrant women in the labour market are even worse (Júlíusdóttir et al., 2013).

2 http://www.sa.is/frettatengt/frettir/alvarleg-throun-avinnumarkadi/ 


\section{General description of the municipality/region}

The increasing demand for labour in the construction and service sectors of the past two decades has resulted in a steady growth within the immigrant population of Iceland, which represents $8.9 \%$ of all inhabitants in $2017^{3}$. Located in the north of Iceland, Akureyri is the largest town outside the capital area. The population has been on a steady increase since the beginning of the $21^{\text {st }}$ century, and the immigrant population has also grown. With a total of almost 18,500 inhabitants in 2017, Akureyri is home to $931 \mathrm{immigrants}^{4}$. Representing $5 \%$ of the population, the town's immigrant population originate primarily from Poland, Denmark, Syria, Germany, Thailand and the former Yougoslavia. $35 \%$ of immigrants in Akureyri have been naturalised and hold Icelandic citizenship. Akureyri offers a relatively varied labour market consisting of skilled and unskilled jobs in various sectors, including the fishing industry, the research and education sector, the health sector and the tourism and service sectors. In March 2018, registered unemployment rates in Akureyri were $2.7 \%$, a relatively similar number compared to the national average of $2.4 \%$.

New research from the University of Akureyri (Burdikova et al., 2018) shows that immigrant women are the most vulnerable people in the labour market in Iceland. Many occupy positions that do not fit with their level of education, despite having received higher education than men. For example, in the survey conducted, $30 \%$ of immigrant women in Akureyri answered that they are in employment that does not suit their background, compared to the same answer by only $8 \%$ of Icelandic women. This difference has a direct impact on the income: just $11 \%$ of immigrant women answered that they earn ISK 300,000 or more per month, compared to $37 \%$ for Icelandic women and $22 \%$ for immigrant men.

The municipality of Akureyri is the main actor responsible for providing immigrants with the necessary support for their various endeavours. The local employment agency, Vinnumálastofnun, is responsible for guiding and supporting unemployed or underemployed individuals to get ade-

3 Statistics Iceland 2017

4 Statistics Iceland 2017

5 https://www.vinnumalastofnun.is/media/2040/mars2018-skyrsla.pdf quate employment. There is also a learning centre promoting adult education which offers both support in the recognition of foreign education and Icelandic language courses.

\subsection{The relationship between language knowledge and the labour market}

\section{Institutions supporting language learning for immigrants}

At least four immigrant women participating in this study experience the lack of knowledge or proficiency in the Icelandic language as the main reason for the gap between their education and their employment situation. The possibilities for language learning in Northern Iceland are scarce, although one institution provides courses on Icelandic as a second language. This institution, SíMEY, is primarily a lifelong-learning centre. Funded by municipalities, trade unions and public and private employers, the main aim of SÍMEY is to increase the level of education in the region, to be in active co-operation with the labour market and to identify the need for lifelong learning, to offer a variety of lifelong learning opportunities for adults and to provide educational and career counselling. More specifically, SÍMEY addresses the need to provide language learning/training courses to non-Icelandic speakers, and many immigrants use its services to learn Icelandic upon their arrival. Their description on their website reads as follows:

"One of the roles of SÍMEY is to provide practical education to individuals in the Eyjafjörður area. We do that by offering several courses both related to work and hobbies. As an example, we offer computer courses, language courses, many kinds of leisure courses and courses that emphasise increasing the individual's potential in work- and daily life. SÍMEY also offers programs that last longer than an average course, and these programs can be evaluated as points in college or as a preparation for university. SÍMEY provides a diverse selection of courses in Icelandic as second language in Akureyri, Dalvík and Fjallabyggð. The courses are based on the curriculum of Icelandic as second language, published by the Ministry of Education, Science and Culture. The project managers and counselors of SÍMEY are ready to help individuals to find out what courses and programs suit them the best. They also help individuals to find ways to finance the courses fees. This service is for free."

As the only institution offering Icelandic lan- 
guage courses for non-Icelandic speakers and helping individuals to secure funding for the courses (most trade unions in Iceland reimburse at least $75 \%$ of the costs), SíMEY seems to provide uncomplicated access for those who wish to improve their proficiency in the Icelandic language. Six of our nine participants have taken at least one Icelandic language course at this institution. Some expressed satisfaction with what they learned during the language classes, while others highlighted the inconsistency between the teaching content and their individual level in Icelandic. Several participants were waiting to attend a course that had been postponed twice and noted that the courses get cancelled if a minimum number of participants has not been reached. Most participants decide to attend Icelandic courses on their own initiative, and there are two main factors which affect their ability to progress in Icelandic: availability of the courses and motivation. By 'motivation', we mean a set of circumstances which allows them individually to be willing and able to learn Icelandic. Those who do not have many opportunities to talk Icelandic in their daily lives, or who feel that the level of the course they have taken is inappropriate, can feel disheartened at their 'slow' progress. Moreover, those who work full-time indicated that they lacked the time, the flexibility or the energy to attend Icelandic language courses.

\section{Language as a pre-requisite for adequate employment}

Language is perceived both by employers and by immigrant women as a hindrance in finding adequate employment, especially in sectors which require frequent interaction with customers. Both employers maintained employees with little knowledge of Icelandic at entry-level positions in their company and argued about the necessity to be highly proficient in Icelandic to access other jobs within the company. Considering the nature of the hospitality industry, fluent communication in Icelandic is a requirement for many employers. In other sectors, speaking Icelandic might be more of a desire from employers than a need; one employment actor we interviewed mentioned that hiring an immigrant could be a challenge for many employers because of language barriers and different social and cultural codes. Hiring someone 'native' somehow guarantees that employers remain within a certain comfort zone.

On the women's side, their beliefs about lan- guage knowledge prevent them from trying to access jobs that fit their education, as exemplified by this participant:

"I'm afraid a little bit as well, like [part-
ner] is always angry with me. Like I'm
afraid that I don't know the language.
I think it's best to explain with an ex-
ample. They were offering a job at this
[place], they are renting cars and they
were looking for someone in the office,
just to hire cars and make contracts...

There is a lot of foreigners coming which is good because then it's enough to have English, but you need to have Icelandic as well. [Partner] was asking me, there was this job, "just send an application there", and I was like "Nei, I don't think I could do it because I don't have so good Icelandic to talk with Icelanders if there is some problem or something", so I was stressed about it and he was angry with me because he thinks I have enough knowledge of Icelandic to do that but I'm still... I didn't feel comfortable, but I sent an application. But ofcourse they didn't pick me. I think they will prefer some Icelander; I honestly think they will prefer someone who is Icelandic." Interview 1, Female, Central Europe

This example illustrates that immigrant women lack confidence in utilising their language skills and their potential to apply for jobs that fit their education. However, language knowledge (or lack thereof) can create exclusion within the workplace; both employers and immigrant women sensed that insufficient proficiency in Icelandic had an impact on their ability to be part of a team, as exemplified below:

"I didn't try to find another job [in the company]. It's how people are thinking, it's like taking the emotions. If they [the co-workers] are thinking "she is a foreigner, she doesn't speak good lcelandic", it's the energy they are transmitting to me, and sometimes I feel like okay, making some mistakes, or I'm not speaking..."

Interview 1, Female, Central Europe 
"No, it doesn't bother me at all [that my staff does not speak Icelandic]. But in a sense, you can sometimes notice it, in the coffee breaks and things like that; they are not really in the conversation, and that can be a difficult thing. I did part of my masters [abroad], and I experienced myself how awful it is sometimes to be the minority and not be able to understand or say a joke or be spontaneous."

\section{Interview 12, Icelandic Employer}

While all participants, whether they are immigrant women, employers or other actors, recognise that knowledge of Icelandic is important to secure adequate employment, one of the actors insisted that one dimension remains as important as proficiency in the local language. This dimension is the personal attitude and the determination of individuals themselves; according to her, motivation and clear boundaries between what jobs immigrant women are willing and not willing to accept is essential to gain access to the right opportunities. She illustrated her reasoning with stories of immigrant women with higher education who have decided not to accept cleaning jobs at any cost; because of the clear prospect those women envisioned for themselves, they were able to (or possibly had to) find better opportunities.

Despite the belief that proficiency in Icelandic is the main and only key to secure adequate employment for immigrant women, the interviews with both women and employers show that there are other actors at play which keep women underemployed, namely the timidity of employers to hire immigrants and the women's hesitation to apply for positions which suit their qualifications.

\subsection{The integration in the labour market through internships}

\section{The structure of internships}

The employment agency of Iceland, Vinnumálastofnun, has introduced job training and learning opportunities for individuals as part of their program. The objective of this set of measures "is to counteract unemployment, to enable people who are searching for a job to maintain their activity, to promote their connection with the economy and create ways for people to improve their possibilities to participate in the job market. Among the labour market measures that the Directorate of Labour manages are courses, work-related measures, educational measures, work-related rehabilitation and consulting." The main activities in place are fully-funded Icelandic courses, partly-funded courses in various areas and the organisation of internships for unemployed individuals. This labourmarket initiative is the most efficient, according to the director for Northern Iceland; $70 \%$ of individuals taking part in an internship remain employed at the end of the internship or find adequate employment elsewhere immediately. This initiative could in theory counteract the issues manifested in the previous chapter, where both employers and immigrant women seem insecure in creating connections with each other.

The internship program is funded by the employment agency of Iceland, which allows companies to accept interns within their team for a set period of eight weeks or six months. This is an attractive initiative for employers willing to find an additional staff member, as it comes without financial pressures for the management, since it is entirely funded by the employment agency, and without having to sustain the promise of long-term employment, since the internship is time-bound. Three of our immigrant women participants were offered or asked to be part of an internship program, two of them were included after they expressed their dissatisfaction with their employment situation.

\section{Experiences of internships}

Acting as a bridge between employers and potential employees, the program does have the advantage of encouraging social change within the workplace; Icelandic employers may prefer to employ individuals with the same language and cultural understanding and may be hesitant to promise long-term employment to immigrants. The program allows employers to "get used to the idea" of having individuals who might have different habits and work ethos before they can be "ready to take them on", to use the words of the director of the employment agency. The initiativee seems equally attractive to potential employees who generally get to stay employed in the company after the internship has ended. One participant also mentioned the benefit of being able to gain experience, to put in on your resume and to build on connections that might result in gaining adequate employment elsewhere. 


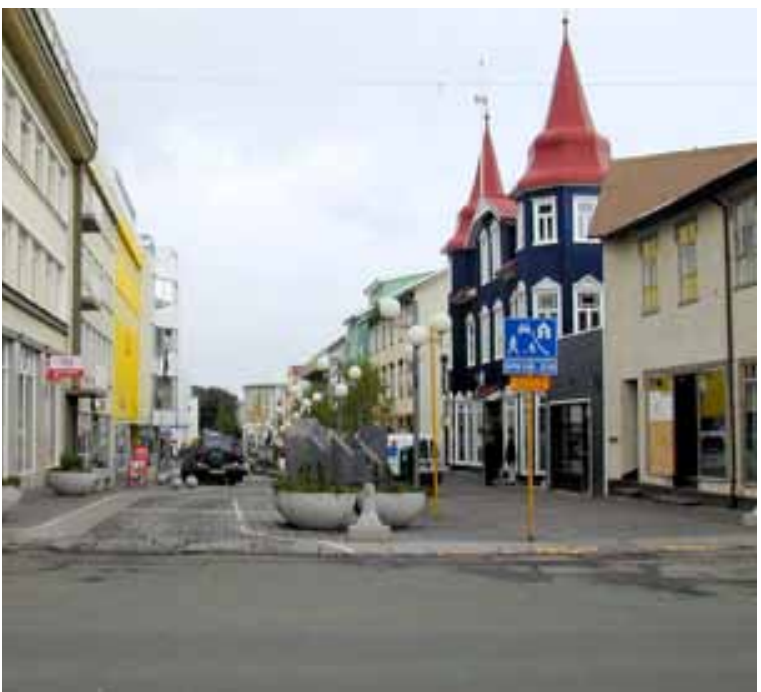

Source: Wikimedia Commons / Thalion77

The mediation of the employment agency in finding both employers and employees for internships is crucial, although we were told by the director of the employment agency that about half of the internships taking place are initiated by employers. The employment agency finds more potential employers on their side and contacts them to know if they would like to benefit from the measure. Companies do not necessarily think of internships as a common tool to find employees, nor do individuals necessarily think of an internship as a way of securing adequate employment. A previous study (Burdikova et al., 2018) conducted in Akureyri shows that the support of the employment agency is irregular, informal and sometimes non-existent. The employment agency does not offer automatically an internship program to individuals fitting certain criteria, but rather responds to individual needs or to the requests of companies.

Of the three women who took part in the program, one of them found paid employment before she could start, and the other completed the internship and was hired by the same company. However, since she could not get her education formally recognised, she was hired for a secondrate position. The third participant was offered an internship as part of a resettlement program for refugees but seemed puzzled by the choice of department she was settled in within the company, since she would have preferred another department. However, it is not clear from the interview whether she was successful in making her preference known to the management.
Creating a connection between potential employees and employers seems like an excellent way of providing immigrant women with adequate employment. However, this measure is only available to unemployed individuals, and it remains out of reach for the many immigrants who are in a situation of mismatch between their skills and education and their employment. None of the immigrant women who have joined an internship and participated in this study are fully satisfied with the outcome of this labour-market initiative. One of them obtained employment in her sector but at a level and salary below her qualifications, while the other has a personal preference for joining another department within the same company, but felt she was not given the opportunity.

Moreover, widespread information about the possibility of joining an internship remains scarcely available, unless you get a private appointment at the employment centre and that the topic is raised during that time. For a municipality worker, the lack of communication and vision of various institutions prevents immigrants to access support to improve various aspects of their lives, including employment. Support programs are available, but there is no adequate outreach program to inform immigrants of the various support possibilities available.

\subsection{Discussion and Conclusion}

This study investigated existing policies and practices which could improve the labour market integration of immigrant women in Akureyri. It focused on the experiences of immigrant women and labour market actors with job mismatch in Northern Iceland, which is most common for immigrant women than for any other group of individuals.

Unemployment is scarce in Iceland. However, job mismatch seems to be a common feature for immigrants in the labour market, particularly for immigrant women. While addressing this issue in personal interviews with immigrant women and labour market actors, we identified reasons which can keep immigrant women in situations of underemployment as well as potential remedies.

\section{Language learning}

Both labour market actors and immigrant women acknowledge that Icelandic is one of the key elements to be able to communicate and navigate appropriately in the labour market in Iceland. In the interviews, mentions of the Icelandic language 
often go hand in hand with a terminology relating to inclusiveness and acceptance. The knowledge of Icelandic is important for everyday communication, to create relationships and to acquire a position within the local labour market.

Learning Icelandic can be a difficult prospect. Most of the participants started to use English as a mean of communication upon their arrival in Iceland and expressed difficulties in immersing themselves in the Icelandic language. These difficulties can have several factors, such as the lack of available learning resources, the lack of time and the lack of opportunities to practice.

Despite being the second largest urban area in Iceland with considerable industry and service, Akureyri has limited services available to immigrants. Icelandic courses are provided in one lifelong learning institution on a supply-and-demand basis, but immigrant women often think that they are offered inconsistently, that many levels remain unavailable and that it can be hard to attend lessons while working full-time. Provisions made within the workplace, such as an hour dedicated to language learning during work hours, might be a good incentive to encourage employees to study Icelandic.

Another hindrance to acquire and use the Icelandic language lies with immigrant women's belief in their performance and ability, which they often undermine. Three women mentioned the need or the wish to speak Icelandic 'perfectly'. They make an unreasonable comparison between native speakers of Icelandic and themselves, Icelandic learners. They experience exaggerated concerns about making errors when speaking and feel anxious, which in turn can prevent them from applying to adequate positions in the labour market. Many of the narratives from immigrant women's interviews displayed fear of rejection and inappropriateness but rarely provided real examples of such situations. Organising language lessons or workshops which also enhance the self-confidence of immigrant women may be a welcome addition to traditional language learning classes.

\section{Overcoming barriers through internships}

Connecting potential employers with immigrant women through internships in Northern Iceland is a valid idea in theory, but it seems under-used in practice. Employers are doubtful about employing immigrants because of prospective difficulties within the workplace, such as miscommunication and conflicting cultural values. Immigrant women are also ambivalent about applying for positions which fit their education because they doubt their linguistic capabilities and their potential. When competing with Icelandic applicants for a job, women are inclined to think that they will always be an employer's second choice.

Joining an internship can be beneficial for both parties to address their concerns and hesitations and is considered an efficient solution to deal with job mismatch. Without sustaining a promise for long-term employment, it gives the employer a chance to consider whether their intern might be a potential employee in the future, while it gives immigrant women an opportunity to immerse themselves in the workplace with tasks appropriate to their skills and education. This opportunity provides women with better confidence, empowerment and more prospects for the future. They might feel more self-assured in applying for positions which match their qualifications.

Most importantly, internships create connections between employers and immigrant women, connections which otherwise would be lacking. Immigrants do not necessarily have extended social networks in their destination country, and everyday contacts with Icelanders might be scarce. In small municipalities (and in small states like Iceland), networks are extremely important to establish connections, to find information and to obtain opportunities. Being able to enter these networks is crucial for the integration of immigrant women in the labour market.

Policies and practices in Northern Iceland lack a comprehensive and formal structure to address the underemployment of female immigrants. There is a lack of consistent information and programs to support immigrant women to achieve their career goals. Opportunities to counteract underemployment are too scarce and often based on a case-by-case basis rather than incorporated into a consistent system. 



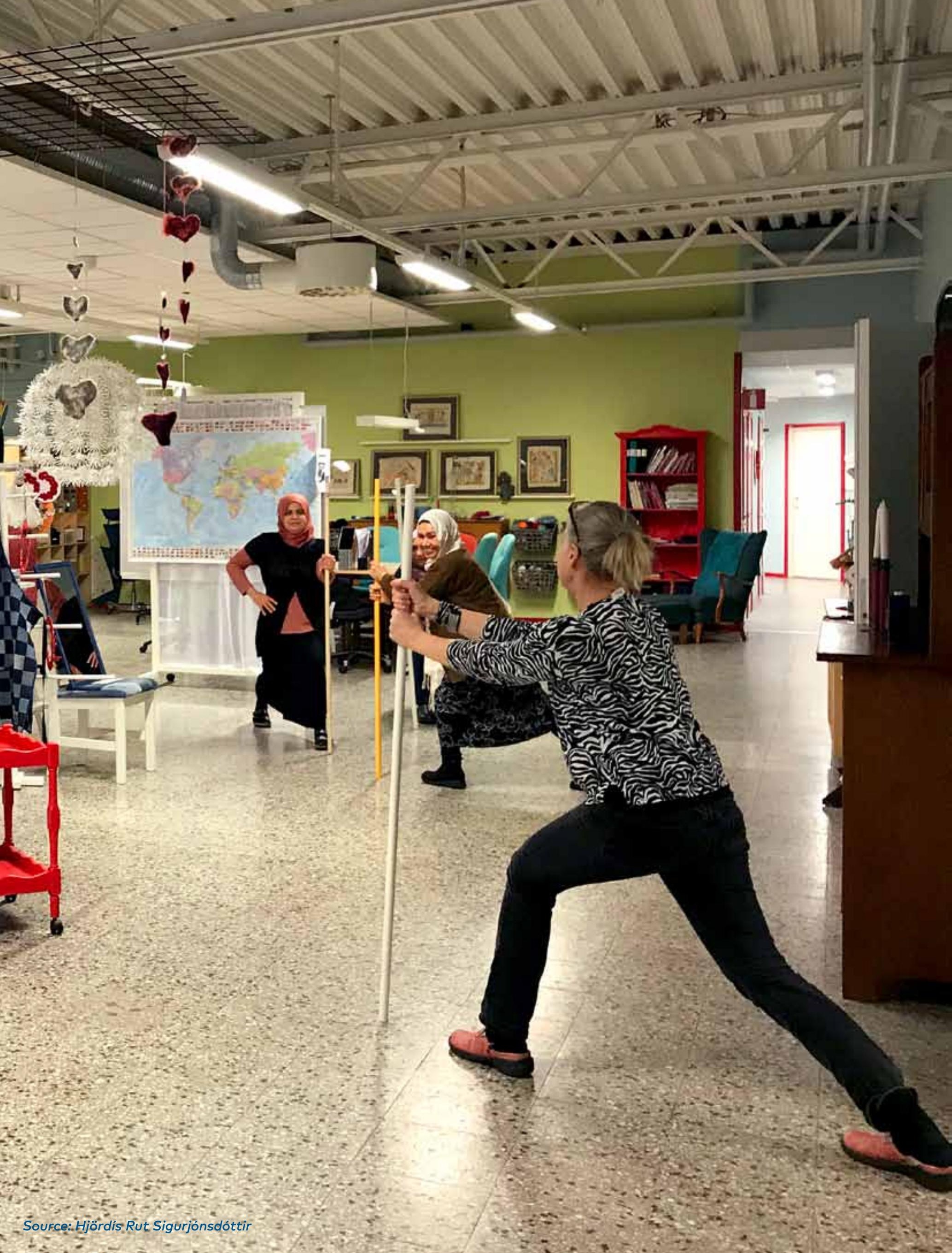




\section{Swedish case study: Labour market integration of immigrant women in Luleå, Sweden}

Authors: Hjördís Rut Sigurjónsdóttir, Mari Wøien and Liisa Perjo

\subsection{Labour market integration of Im- migrants in Sweden and Luleå}

In Sweden, the share of the foreign-born population has been increasing over the past few generations, and it has intensified in the last few years. In 1930, $1 \%$ of the population in Sweden was foreign born, while in 2018, $18.6 \%$ of the population was born abroad (IFAU 2017:4, Statistic Sweden, 2018). Between 2009 and 2015, the share of foreign-born increased from $14 \%$ to $17 \%$ (Swedish Public Employment Service, 2016), and in 2016, immigration to Sweden reached historical highs (Heleniak, 2018). Over the past decade, the composition of immigrants to Sweden has largely been characterised by humanitarian immigration. It is a major destination country for asylum seekers in comparison to other industrialised countries, and in 2005-2014 the country received the largest share of asylum seekers in the OECD (Swedish Public Employment Service, 2016).

The challenges that the foreign-born population, and in particular refugees, face when entering the labour market are actively debated in Sweden. Statistics show a clear difference between the Swedish-born and foreign-born population in relation to the labour market. Data from 2015 shows that the relative unemployment of 15-74 years old population born in Sweden was 5.4\%, whilst 31.6\% was outside the labour force. Among all foreignborn individuals in the same age group, the relative unemployment rate was $16 \%$, and $40.5 \%$ was outside the labour force (IFAU, 2017). Considering the different groups of immigrants, it is evident that people with a refugee status have a weaker starting point for entering the labour market compared to than those arriving in Sweden as labour migrants (Karlsdóttir et al., 2017). Refugees primarily arrive from Africa and Asia, and the labour market situation is particularly challenging for this part of the population. Among the African-born, the relative unemployment rate was $30.7 \%$, and among Asian-born it was 23.4\%. Respectively, $51.9 \%$ and $46.1 \%$ were outside the labour market (IFAU, 2017).

Various studies have analysed the reasons behind the problems of labour market integration of immigrants and refugees. IFAU (2017) identifies the following interconnected issues as the main challenges:

Lack of formal education, especially secondary education

- Limited skills in Swedish

- Limited access to informal networks

Employers high requirements on formal education and Swedish language skills

Discrimination

Studies of earlier migrant cohorts show that the chance of being unemployed decreases over time. On average, it takes 5-10 years for people to achieve full-time employment. Meanwhile, statistics and studies show that newly arrived foreignborn women face more challenges entering the Swedish labour market compared to their male counterparts (Swedish Public Employment Agen$c y, 2017 a)$. The process is often slower for women due to lower levels of education, coupled with family situations including child care (Karlsdóttir et al., 2017), and as this case study will show, difference in cultural values.

Immigrant women without refugee status also have a challenging labour market situation compared to Swedish-born women. In 2016, $14.8 \%$ of foreign-born women between 15 and 74 years were unemployed, compared to $4.5 \%$ among Swedish-born women of the same age. For men in this age group, registered unemployment was higher than that of the foreign-born women, at $16.4 \%$. However, foreign-born women were found to be outside the labour market to a much larger 
extent than foreign-born men: $33.8 \%$ on women in comparison to $23.2 \%$ of men (Swedish Public Employment Service, 2017a). In general, women are more likely to be economically inactive than men in the same category whether they are native born or emmigrated from inside or outside the EU. This difference is however much more pronounced between men and women born outside the EU than the native-born (Grunfelder et al., 2018; Sigurjonsdottir, H. \& Norlén, 2018).

In addition to high unemployment and the higher share of foreign-born women outside the labour market, these women are also underrepresented among those participating in the different measures provided by the Public Employment Services, such as integration programmes and supported employments schemes. This is particularly clear when it comes to women born outside Europe (Swedish Public Employment Service, 2017b). On the other hand, women make up the majority of participants in language courses for immigrants in Sweden as well as in Finland, Denmark and Norway. Participation rates in Sweden are higher than in the other countries. This may be explained by the open and unrestricted access to SFI language courses that are not restricted by time limits and can be completed by students at their own speed (Sigurjonsdottir, H. \& Norlén, 2018).

\section{Tools and challenges for labour market integration}

The Swedish Public Employment Service (Arbetsförmedlingen) is the main national actor working with labour market integration issues, and it consists of a national agency as well as regional agencies across the country. In 2010, the Swedish Public Employment Service was given the responsibility for the overall integration of newly arrived immigrants to the labour market. These efforts are facilitated in co-operation with various actors such as municipalities, county administrative boards, the National Migration Agency and Swedish Social Insurance Agency.

Newly arrived immigrants between 20 and 64 years with a residence permit as a refugee, quota refugee, person in a need of protection, and those who are close relatives to one of those, are entitled to an introduction programme involving language learning, a labour market integration plan and social benefits. The labour market integration plan identifies actions that facilitate the transition onto the labour market, such as Swedish lan- guage education, employment preparations (e.g. traineeships or validation of education and experience) and a civic orientation course about Swedish society. The activities correspond to a full-time 40-hour workweek, and the establishment period typically takes two years (County Administrative Boards of Sweden, 2016). Although the bulk of the time is devoted to language learning, two years are usually not enough to master Swedish or any another Nordic language (Harbo, Heleniak and Hildestrand, 2017). With high language requirements from employers coupled with general educational demands, the barriers are often difficult to overcome for immigrants entering the labour market (Aure, 2013).

\section{Immigrant women as a specific group}

In Sweden, there is a clear gender divide in the employment rate of newly arrived refugees in the initial stages following their arrival to the country (Sigurjónsdóttir and Norlén, 2018). As seen in Figure 1, however, this difference diminishes with the length of stay in the country (ibid.). Based on figures following immigrants arriving in 1997, the gap has been closing gradually. After 10 years, the employment gap between males and females was $13 \%$, but there is barely any difference in the employment rate between males (69.6\%) and females (69.3\%) after 20 years.

The specific challenges that foreign-born women face in entering the labour market were recognised by the Swedish government in 2017. The Swedish Public Employment Service was responsible for making an action plan for increased participation of foreign-born women in work and education in 2017-2018. The plan addresses all foreign-born women, but there is a special focus on women with low levels of education and limited work experience. The activities in the action plan include increasing awareness among employers and co-workers about equality and human rights; mapping the issues that create barriers for foreign-born women to enter the labour market, in order to ensure a sound basis for better decisionmaking; and increasing the participation of foreign-born women in employment services (Swedish Public Employment Service, 2017b). Higher levels of education improve the chances of entering the labour market for both genders. However, this is no guarantee for finding employment corresponding to educational level to same extent as native-born Swedes. This resonates with the situ- 


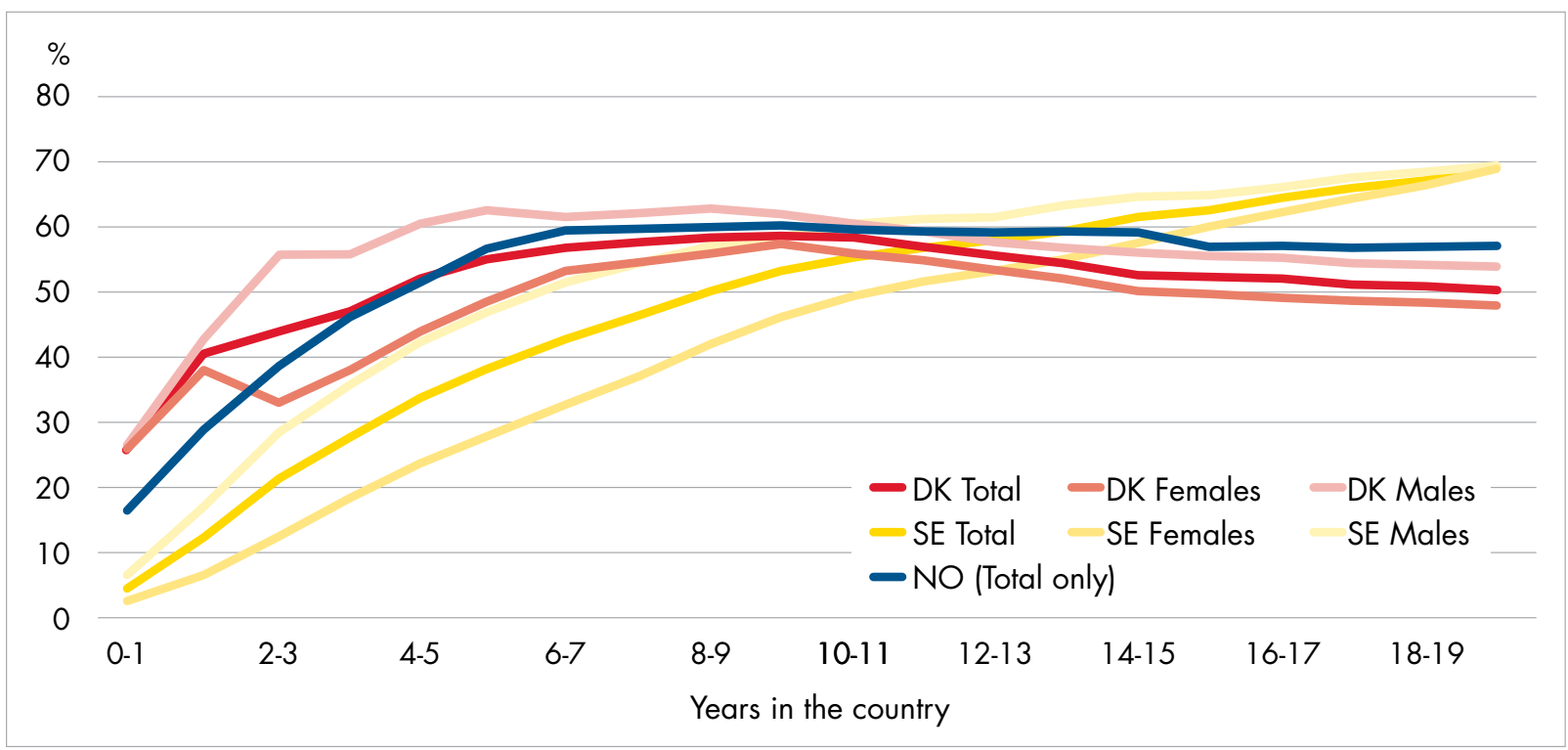

Figure 1. Employment rate. Data source: NSIs. Note: DK: 2015. DK \& NO: immigrants from non-western countries. SE: refugees who have been granted asylum

ations of mismatch seen both two decades ago and today (Karlsdóttir et al., 2017; Knocke, 2000).

In the Swedish government's budget for 2018, further reforms are proposed to increase the labour market participation of foreign-born women. It will be made possible for them to study Swedish while on parental leave and increase their opportunities for starting enterprises. More funding will also be provided for adult educational associations for activities targeting foreign-born women, to increase their participation in education that in turn may increase their chances for employment (Swedish Government, 2017).

\section{Labour market integration policy and governance in Luleå}

Luleå's labour market generally reflects the Swedish labour market. The service sector accounts for the largest share of jobs, whilst the manufacturing industry is shrinking (Luleå kommun, 2017). From being an industrial centre for iron ore extraction, to a university and a regional centre where data centres complete the picture, Luleå's image has drastically changed. The industrial sector is still important, but the service sector including the trade and tourism industry, has grown and now dominates the labour market. Luleå municipality is the largest employer with almost 7,000 employees, and many of the county authorities of Northern Sweden are located in the city. The county hospital is also in Luleå, which is one of the major workplaces (Luleå kommun, 2017).
There were approximately 43,000 jobs in Luleå in 2016. This number was more or less the same as the number of residents in the age group 20-64 in the city. Therefore, the population increases during daytime by several thousand people that commute daily to Luleå. The unemployment rate is lower than the national average and the proportion of foreign-owned companies in the city is somewhat higher than the national average (Luleå kommun, 2017).

The share of foreign born in Lulea has increased from $7.1 \%$ in 2002 to $10.7 \%$ in 2018 as shown in Figure 2. The share is significantly lower than the national average witch was $18.6 \%$ in 2018 (Statistic Sweden, 2018).

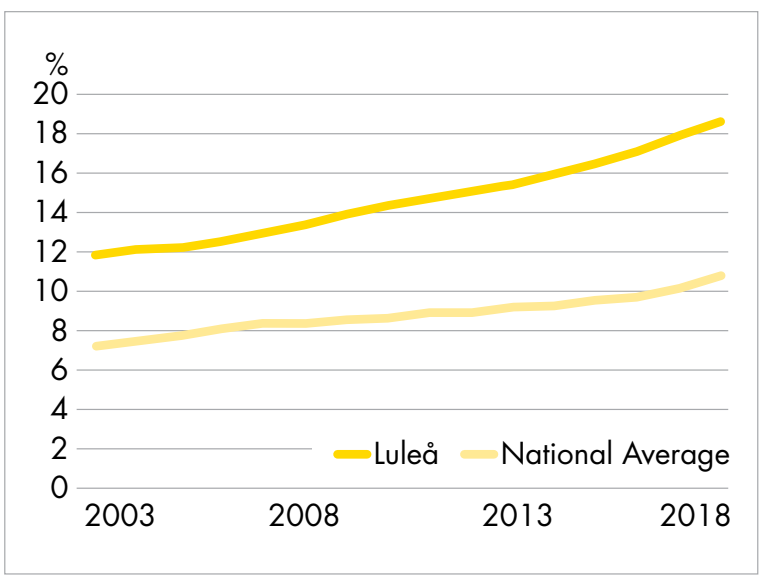

Figure 2. Percentage of foreign born between 2002 and 2018 (1st of January). Data source: SCB 
At the same time, immigration is seen as a necessary part of the population development for the region. A significant proportion of the population will soon be retiring; a proportion larger than the natural population increase can account for (Mats Lindell, 2015). Immigrants and their skills are thus needed in order to cope with the demand for labour and competences, which is stated in the regional action plan for integration and regional development (Mats Lindell, 2015). Authorities in Luleå also acknowledge the importance of ensuring the right competencies for the city's future and have published a report specifically about the topic (Kompetensförsörjning, 2016-2018). To keep up with the demand it is considered important to improve validations on both education and experience of immigrants and to increase the availability of applicants with the needed skills and competences (Luleå, 2015). Additionally, making the most of the skills and competences that the immigrants bring with them by promoting the immigrants' integration pathways creates important synergies between the individual immigrant's needs and well-being (Karlsdóttir et al., 2017). To ensure that they reach their full potential in Swedish society and for themselves, it is important to speed up the language learning to reduce the risk of the competences losing value over time (Mats Lindell, 2015).

Measures to help immigrants to enter the labour market are often included in the actions for overall labour market inclusion. This includes others that are unemployed and for some reason face difficulties entering the labour market and the Swedish Public Employment Service in Luleå has various tools for bringing these people back into the labour force. Considering the groups with an immigrant or refugee status, the general experience in Luleå is that immigrant women register at Public Employment Service to a lesser degree than immigrant men, and by not being registered they forfeit the financial benefits and the access to labour market measures provided. According to information from Public Employment Service in Luleå, it is difficult to reach out to those who are not registered. However, it is important to find ways to inform them about their rights, not least those that are particularly difficult to reach. The reasons behind not registering can be various, such as unawareness and uncertainty surrounding the Swedish system. Many have a good reason to be sceptical of authorities, a perspective that must

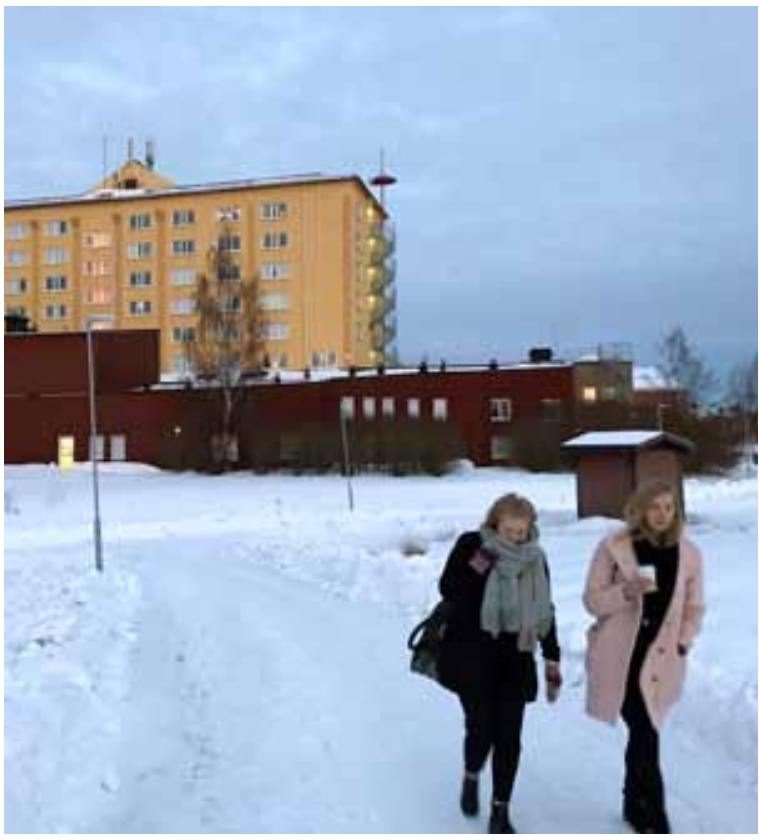

Source: Hjördís Rut Sigurjónsdóttir

be considered (Maria Karlsson, interview 5. December 2017).

\section{Integration as a two-way process}

Integration is meant to be a two-way process and therefore it is important to consider involvement of all actors, when it comes to labour market participation. Alongside the immigrants themselves, it is important to include potential employers, as well as considering the general reception of immigrants in a society (Hagelund and Kavli, 2017), especially considering demands and requirements. The Public Employment Service has programmes involving both immigrants and employers, where the involvement of the latter is considered important for the overall outcome. Their willingness to actively take part in the integration process is important to get more people onto the labour market. Moreover, employers may also influence the public opinion and counteract discrimination.

For example, there are some indicators that show that the requirements of language courses are, in some cases, inconsistent with the needs of the labour market. Studies show that employers focus on language skills beyond reasonable needs (Karlsdóttir et al., 2017, Aure, 2013). This concurs with Maria Karlsson's, the section director for Public Employment Service in Luleå, understanding of the matter. She believes that employers need first and foremost to change the high requirements regarding language skills, which would be in line with 
the changing circumstances of Swedish society in general (Maria Karlsson, interview 5 December 2017).

However, the experience at the Public Employment Service in Lulea is that insufficient language skills remains the main barrier regarding labour market integration, not only when it comes to the general activities undertaken at the workplace, but also for the social participation and the work environment regarding e.g. acceptance of a new culture (Maria Karlsson, interview 5 December 2017). Beyond labour market participation, these factors combined have also been understood to correspond with the overall earning potential for immigrant women. There is an earning gap between native women and immigrant women, although immigrant women with a Swedish partner tend to be associated with a quicker accumulation of country specific human capital, such as language and culture (Kotyrlo, 2014).

The labour market in Luleå will seemingly be dependent on immigrant skills and competencies in the future, as the natural population increase does not correspond to the needed demographic development. The initiativess put in place by the Swedish Public Employment Service are attempting to grapple with a heterogeneous group of immigrants, ranging from none to low levels of education and highly skilled immigrants. Immigrant women are thus evidently vulnerable to labour market exclusion. The following chapters will consider measures put in place to tackle these challenges.

\subsection{Analysis of the labour market measure: Korta Vågen}

Korta vägen is a fast track programme for immigrant academics to enter the Swedish labour market. Participants must have completed three years of university studies or more to be accepted into the programme. The Swedish Public Employment Service is responsible for the programme which is carried out by universities, colleges and other educational agencies across the country.

In Luleå, LTU Business, owned by Luleå University of Technology, has carried out Korta Vägen since 2010, when it was established. Around 150 individuals from across the world have participated in the program. A new group of participants starts twice a year, with 15 to 20 participants each time. Applicants that meet admission requirements regarding education level are invited to an interview where it is evaluated individually whether the program is likely to ease her/his way into the regional labour market. Considered are Swedish skills, motivation, engagement and whether the background education fits the regional labour market in one way or another. Then the potential to find an appropriate internship fitting the needs are estimated. About half of the applicants are accepted into the program, and in some cases, a slightly higher Swedish level is needed since all teaching and communication is in Swedish.

The program is underway for 12 to 26 weeks, where language teaching is intertwined with knowledge dissemination about the Swedish society, practical things for job search such as making a CV, personal letters and how to perform better in job interviews. Skills useful for the hiring process, in the Swedish and local labour market, are trained with help of a staffing company. The Swedish language learning is both general and in relation to each profession aimed to prepare the participants for forthcoming internships, one of the programmes main objectives. An internship has proved to open the way for employment or for participants to discover new paths to better match their skills to the local labour market.

The programs results show that the program works quite well for those who are entitled to participate. About 70 percent of the participants get jobs in their field of work. The participants in the program have all high competences but struggle to utilise it on the Swedish labour market. Both participants and those responsible for the programme seem to be satisfied with its function and can hardly think of anything that needs to be refined. The program in Luleå is based on a very personal approach, with relatively small groups of participants and in a community with relatively small population. The employees' approximation to reach out to the companies in the search for internships and towards the participants is very personalised.

\section{Experiences with Korta vägen}

The programme is tailored to each individual where competence mapping and a guidance from a counsellor is provided. All the participants in Korta vägen, in this study, consider the lack of knowledge of the Swedish language to be the main hindrance for entering the labour market. Before starting Korta vägen, all the interviewees have studied the language at SFI (Swedish for immigrants), which is accessible for free; however, it can involve a bit of waiting time before entry, dependant on attendance. One of the women interviewed had to turn 
back to SFI to improve her Swedish before being admitted to Korta vägen:

$$
\begin{aligned}
& \text { "To find a way to the labour market } \\
& \text { the Swedish language learning must } \\
& \text { be prioritised [...] Without the language } \\
& \text { you are left outside of the society. It can } \\
& \text { take a long time until you dare to talk, it } \\
& \text { took me over two years to dare." } \\
& \text { - Interview S, female from } \\
& \text { west Asia. }
\end{aligned}
$$

One of the participants with a degree in literature explained how she felt almost illiterate, isolated and uncomfortable without knowing the language. For her, learning the language was the key factor in becoming independent and functioning within society. Although English is widely spoken in Sweden, the Swedish language is needed to fully participate in society. This matches the experience to the four participants in Korta vägen that have very good English skills. Isolation, was often mentioned in the interviews in connection to being without a language in a new country, in addition of being outside the labour market and not participating in regular social activities. Due to the importance of Swedish skills for labour market integration Korta vägen emphasis on intensive language learning and no other language is allowed during programme hours. This is described as very effective by the participants and much more so than the SFI. The groups are smaller, and the students are on a comparative level, with many years of education. Two women, fluent in English, explained how they believed that they would achieve more and integrate further than they did with the English skills that they had acquired:

\footnotetext{
"I learned that only speaking English was problematic, even though most Swedes speak English. The daily life is in Swedish and it is necessary to learn the language."

- Interview B, female from Asia.
}

"Learning Swedish is the most important thing, if people want to understand the society and be part of it. Also, when finding a job. Having English as my native language did not help me to get a job before I learned Swedish."

- Interview D, female from Asia.

\section{Internship and network}

Apart from the language, immigrants' network is often very limited, but it is an important factor when job searching in Luleå. The programme substitutes this deficiency with the employees' network, with internships and by having them invited to breakfasts at businesses in Lulea to improve their social competences and to start their own network building.

Providing the participants with an internship is one of the programs primary goal and one of the main methods for making a connection with the labour market. The programs employees open their own personal networks in the search for internships. The success rate in finding an internship depends on the participants education and experience. In some cases, contacting two companies is enough while it can take up to ten attempts:

$$
\begin{aligned}
& \text { "Both me and my colleagues' have great } \\
& \text { networks. I have worked in Luleå my } \\
& \text { whole life. I have worked in the university } \\
& \text { as a teacher and many of my former } \\
& \text { students are working in the local com- } \\
& \text { panies. They [the participants] get ac- } \\
& \text { cess to my network. Sharing it does not } \\
& \text { cost me anything." } \\
& \text { - Interview, program leader Korta vägen. }
\end{aligned}
$$

The responses are usually positive when companies are contacted to provide internships, however that does not mean success in all cases. The effort involved in finding an internship varies depending on the participants competences and the need of labour in the relevant sector and the companies' ability to receive interns. Uncertainty towards foreign education often makes employers reluctant to hire foreign inhabitants. An uncertainty that LTU Business and its employees' reputations can help to bridge:

$$
\begin{aligned}
& \text { "The problem in the beginning is that } \\
& \text { they don't know you. You must be ap- } \\
& \text { proved by someone." } \\
& \text { - Interview F, female from } \\
& \text { west Asia. }
\end{aligned}
$$

Korta vägen provided most internships through its connections in the local community, but some of the participants have also managed to find internship or jobs through their own network. A network they got through people close to them or a net- 
work the managed to build up through their participation in Korta vägen.

\section{Personal effort}

All the women experienced difficulties getting a foothold in the new country. Those four women that had children went through this struggle and stayed in Lulea, mostly for their children, besides the barriers involved in integrating to a new country and a new culture. Either the children were old enough to express their will to stay or that the parent believed it was in their best interest.

Despite the general satisfaction with the program, among the women in the case study, a success does not come without personal effort and a positive attitude is very important. Along with the opportunities provided by the program the participants must work hard to make the most of it:

\footnotetext{
"They got my foot in the door, by helping me to find internships [more than one]. It would have been difficult to find a job direct. Internship really gives the opportunity to show what you are capable of and also gives the opportunity to learn new things. The employer also gets the opportunity to learn to know us." - Interview D, female from Asia.
}

Based on the interviews, flexibility eases the process of finding a job or internship. Some even described it as unrealistic to believe that they would be able to find a job in Sweden according to their education right away:

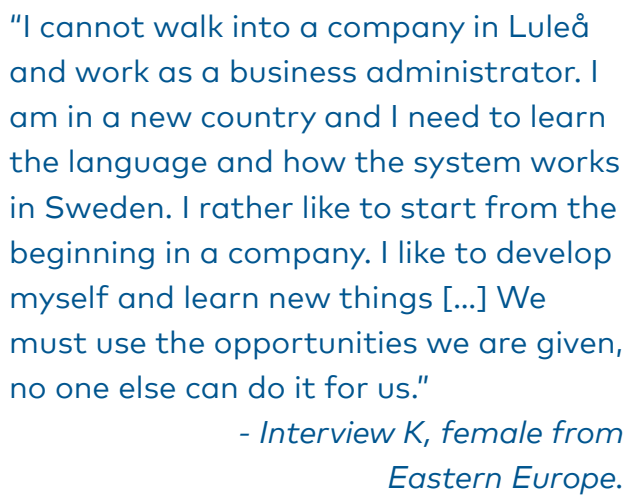

Some education fits the local labour market to a lesser degree, making it harder to find internships according to the participants education. In such cases, the program leaders try to find different alternatives. Two of the interviewees had accept- ed internships in a school to find out if they were willing to take a new path and become teachers. The teacher shortage is excessive but the effort to make a career change and become a legitimate teacher is considerable. Pedagogic education is required in addition to existing university education and before people can begin, a certain level of Swedish and English is needed. One of the two participants going or thinking about taking this path shows a certain serenity towards this extra route she must take to get a suitable job. However, at the time of the interview it was unclear how much of her former education would be evaluated for the teacher education and she explained that more than two years of extra education would be too demanding. The other woman explained a different experience and often described her situation as difficult. Her hopes were to work as an engineer but her first internship did not meet her expectations. She felt the job tasks allocated were routine and not suited to her education and quit after a few days. She described frustration and felt that her education and substantial experience from teaching before arriving to Sweden was not valued. She then considered becoming a teacher but has not decided if she was willing to pursue the additional education. Due to her low levels of language proficiency she is now struggling to meet the Swedish requirements needed to pursue this additional education and the road to employment in her chosen profession is long.

\section{Different work cultures}

Overall the participants had similar experiences with Swedish work culture. Many described the working environment in Sweden as better than in their country of origin. The main reason named was the absence of hierarchy:

$$
\begin{aligned}
& \text { The chief is open and friendly. Not above } \\
& \text { and controls with hardness. She gives } \\
& \text { me feedback on my performance every } \\
& \text { now and then and encourage me. It is } \\
& \text { not like than in [her country of origin]. } \\
& \text { - Interview G, female from Asia. }
\end{aligned}
$$

Other factors were named when unfolding the Swedish work culture such as the importance of participating in "fika" or the coffee break. This has been emphasised in Korta vägen since it is considered important for integrating in the work place; not socialising is even seen as distrustful. 


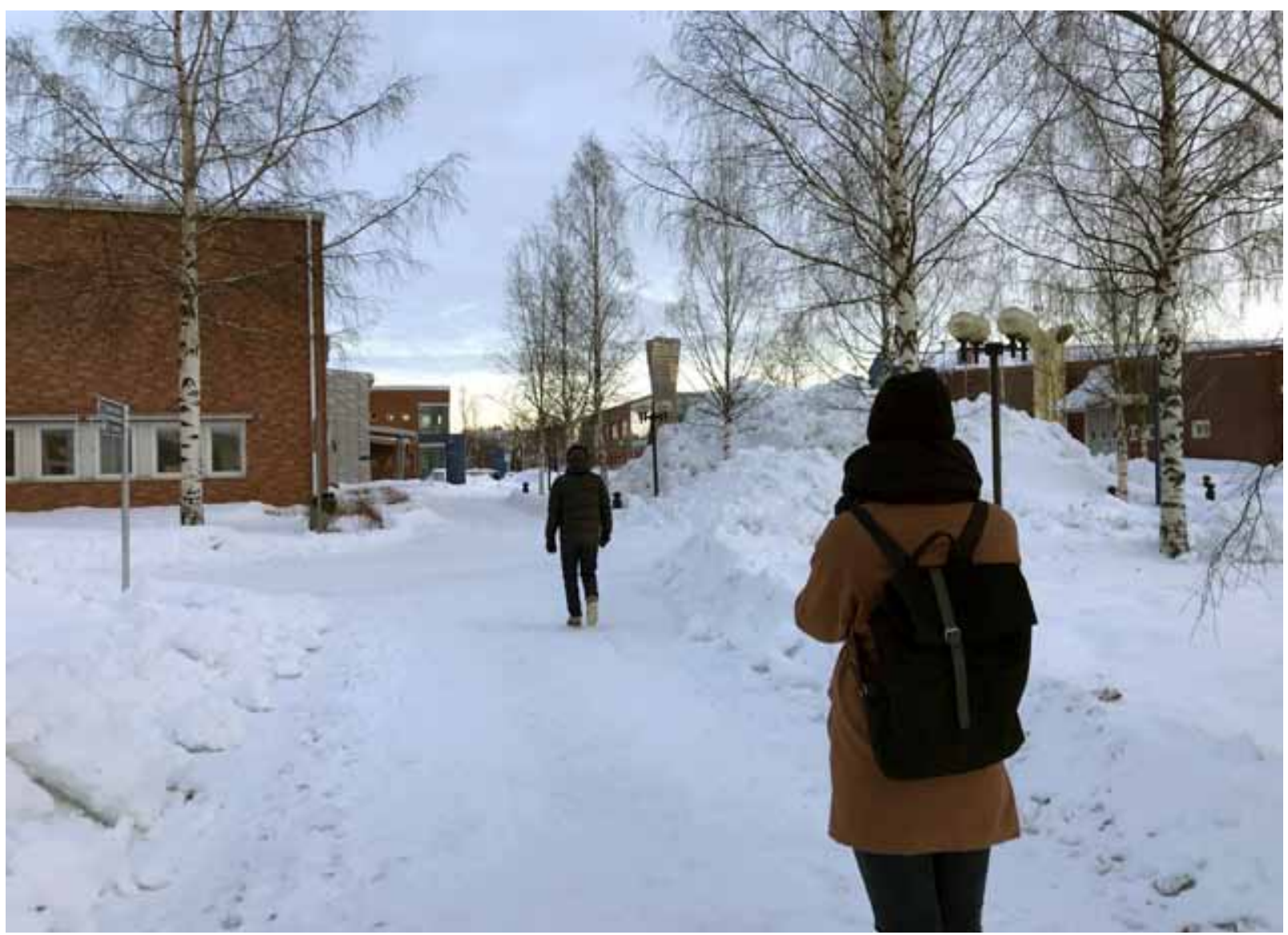

Source: Hjördís Rut Sigurjónsdóttir

Most talk about kindness and being well received by the employees, however it is obvious that attitude that can be interpreted as discriminative is also apparent. Some minimise such attitude and describe how they are not letting it affect them, others talked about shown resistance and others say they hardly become aware of anything negative.

\section{Outside Korta Vågen}

Korta vägen and Bazar are only suitable for women or people with a certain skillset and leave out others that do not have access to the measures. Two interviews were conducted with women outside Korta vägen to get a wider perspective. One that had nearly finished her bachelor's Degree when she fled her country and did not fulfil set requirements. The other felt the classes in Korta vägen were not tailored sufficiently to their needs and left the programme. Instead, she decided to try finding appropriate employment on her own, and at the time of the interview she was adding to her education in adult learning and had managed to find an internship on her own.
The ability to find employment has proved a challenge. Struggling to reach the employers and get feedback on their job applications have seemingly trapped both women interviewed in a circle of rejections and left them feeling powerless. When they successfully entered traineeship, it became evident that there were certain structural barriers regarding the work experience they were undertaking, where their qualifications are often being set aside and leaving them without the chance to prove their abilities.

In their meeting with the Public Employment Service, both interviewees felt that their experiences and education were not adequately recognised, as they were frequently offered jobs that had no educational requirements. One of the women, who holds a bachelor's Degree in a profession that is hard to match with the local labour market, described her frustration. This was also echoed in the interviewee with a refugee background who recently commenced her studies at Luleå Technical University. When asking for help to find jobs, these were largely irrelevant to her previous studies in economics: 
"When I wanted a job, I asked the Public

Employment Service if they could help me find a job, which they did. But the jobs they offered were mainly jobs in restaurants or in the healthcare sector or retirement homes."

- Interview $H$, female from the Middle East.

This situation may be tainted by the low levels of Swedish acquired by the individuals wishing to enter the labour force in specialised fields. Nevertheless, the handling of the abovementioned case demonstrates that there are still structural aspects of helping e.g. refugees and immigrants to find relevant work and traineeships, and by the same mean helping them reach their full potential and become productive members of Swedish society.

Among refugees, there are also those arriving to Sweden who started their education in their home countries but were unable to complete their education due to the outbreak of war. The woman interviewed had had one year left of her four-year bachelor's degree in Economics, but because her degree did not correspond to the Swedish qualification merits, she needed to start a new degree from scratch after getting her high school diploma validated. The interviewee expressed a wish for a system which included options for students like herself:

"[...] When I was trying to find information as to what I was supposed to do; could I start studying at the university... and when I wrote my personal officer [at the Public Employment Service] they could never really give me an answer. They gave me answers, but when I told them: I have studied this, and I'd like to study that - what should I do, how do I get there? They couldn't really help me. It wasn't obvious to me at all, what I was meant to do [...] I wanted a study plan, but they couldn't help me. They only know their own system."

- Interview $H$, female from the Middle East.

At the same time, the interviewee conceded that the officer appointed to her could not do anything beyond his or her power.

\section{Findings}

Korta vägen admission requirements and interview provides the programme with skilled and motivated clients. Likewise, it provides an opening for a rather quick labour market entry for people with high competences. That benefits both those who meet the criteria and the local labour market which is in need for skilled labour. With increased skills and knowledge in the Swedish language and the local labour market, along with more connections to the local community the confident grew among the interviewees. The success and the improved self-confidence in new settings was dedicated to Korta vägen by participants. The programme provides the opportunity to compensate skills that needed to be improved, added new skills especially language skills and bridged the gap between the Swedish labour market and their skillset and experience. This reaches a long way, however for the programme to work well the participants motivation, flexibility and hard work must be included.

As far as it covers Korta vägen proves to be a successful labour market measure but can only reach certain groups of immigrants. The question of how to handle those that are falling between chairs; those without qualifications but who are well underway with their studies, the ones that hold degrees and have work experience. It is seemingly a challenge to find a canal for those who fall under these categories and risking their former efforts to increase their abilities becoming worthless.

\subsection{Analysis of Labour Market Measures: Bazar}

Although it is evident that understanding the language is the key to enabling integration into Swedish society for these women, it is also important to recognise the underlying factors that may impact on the speed of the language learning process. This chapter will touch upon important aspects of self-empowerment and confidence, social networks and support systems, alongside acquiring sufficient language skills, as barriers facing immigrant and refugee women in Sweden. This will contribute to a fuller understanding of the challenges ahead. As the women interviewed either worked at home taking care of the household before moving to Sweden, their self-confidence as part of the workforce necessarily needs to grow before entering the Swedish work force. Following from the interviews conducted at Bazar, it seems clear that 
allowing the women to discover their opportunities and roles in society, happens in tandem with language learning. Rather than focusing solely on building language skills, it seems necessary to continue working on their self-confidence as well. Daring to step out of one's comfort-zone and take part in the new societal surroundings is daunting, but arguably rewarding.

\section{About Bazar}

Norrbotten county has an unemployment gap of $22 \%$ amongst foreign born people, compared to $6.5 \%$ for the native-born (Interview Programme Manager, 5 December 2017). Women with low levels of education are overrepresented in the group of unemployed foreign-born (ibid). Recognising their potential as a group, Luleå municipality's labour administration-initiated Bazar in 2015 as one of four projects to support foreign-born women that are farther away from the labour market. It focuses on improving their Swedish language skills and increasing work experience. This initiative is based on Malmö's programme 'Yalla-trappan', supporting women to eventually support themselves as part of the labour force, or through education (ibid). Bazar's pilot period has proven a useful tool for the integration of foreign born women and will continue as an established social enterprise in the years to come (Interview Programme Manager, 5 December 2017).

Bazar is a social service for foreign born women only, a service that the organisers have realised is important for establishing a safe environment for learning Swedish and to be able to ask questions and even joke about aspects of female life. It is also an arena for asking Swedish women about Swedish society (Interview Programme Manager, 5 December 2017). There are 15 women participating in each round of the project, who meet every morning to talk about different topics. This is both based on the teacher's plan as well as in accordance to the participant's wishes. Communication happens by demonstrating both physically and through drawing and writing. In the first phase there is a focus on enhancing and developing already existing skills, followed by a more tailored scheme for the individual participant according to their needs (Interview Programme Manager 2017). Apart from this opportunity, the women at Bazar may also work in the Bazar café when they have reached a certain level of training, where the women sell what they themselves have produced.
Bazar plays an important role in ensuring the women's self-development and confidence boosting. The programme places a lot of emphasis on the individual's personal responsibility to integrate into Swedish society and provides the language skills and social tools for doing so. Despite the language course Swedish for Immigrants (henceforth SFI), the program managers at integration programmes like Bazar see that women have difficulties breaking away from the traditional roles assumed in their countries, and thus tend to have a harder time integrating into society. Not exposing themselves to the language and becoming dependent on their children and husbands, the women are struggling to integrate to the same extent as their male counterparts. It was the women's situation that first inspired programs like Bazar (Interview Program Manager, 5 December 2017).

There are also exchanges and study tours between Bazar and a similar programme called Esperanza, where women are encouraged to meet and create a network, whilst recruiting participants that need a different level of training. Esperanza is an international women's organisation, which main objective is to 'give women, children and young adults a meeting space for multicultural co-operation' and furthermore focus on the power of social networks and the important exchange of cultures (Visit Luleå, n.d.)

\section{Bazar, the labour market and language requirements}

Bazar gives the opportunity to practice the language in a safer environment. With an SFI teacher who comes by once a week, the women are taught Swedish grammar, syntax and vocabulary (Interview Programme Manager, 5 December 2017). This is an important part of the language learning process, but considering Bazar's experience, allowing the women to practice the language in an environment where they may develop their language skills at their own pace, is highly valuable.

Entering the Swedish labour market requires a certain level of Swedish as a (written and) spoken language. However, recognising what level of Swedish fluency is sufficient for entering the labour market, is difficult. These requirements may seem daunting to the immigrants and refugees attempting to enter the labour market. As several of the interviewees working as employers of immigrants and refugees emphasised, the language requirements set are often too vague and too de- 
manding of these newly arrived people, and furthermore hinders them to develop their language at a faster speed through practicing at work. Moreover, there is seemingly a contingent that the language is tied to the quality of work performed:

"I think there is a prejudice that equates
poor Swedish language skills with not
knowing anything at all. One forgets
that you might have a wealth of knowl-
edge despite not knowing Swedish."
- Interview Programme Manager.

Some of the women arriving as refugees additionally do not know how to read or write. Learning Swedish thus becomes extra challenging, but nevertheless not impossible.

Aside from acquiring language by practicing, Bazar also works to ensure an understanding for working life in Sweden. This is done by introducing health regulations, norms and customs for food preparation in their Bazar-run café and through events hosted by the programme. The program managers also take their time to flatten the hierarchy by participating in all the activities.

\footnotetext{
"It is very important to be one of them. When I'm in a project, I immerse myself in that project. They know I'm the boss other places, and sometimes they tell me that I shouldn't clean, as I am the boss. But that's just not how it works for me. I am there, all the time. And when you're there you talk about everything. Cleaning products even! And this is how your language develops [...] I think it is extremely important that we are all the same here."

$$
\text { - Interview Programme Manager }
$$
}

Evident from the interviews conducted with the women participating and the women running the programme, it is important to focus on the variables enabling language learning, such as confidence and societal norms. Languages are culturally embedded, and thud needs to be treated as an integrated part of understanding Swedish society at large.

\section{The Bazar women}

For women that are either struggling with Swedish or indeed are illiterate, finding their own way to Bazar is very rare, according the Bazar's pro- gramme manager. As all immigrants and refugees are required to register at the Public Employment Agency in order to receive support funding some women are encouraged to participate in programmes such as Bazar for a tailored traineeship position (Interview Programme Manager 2017). It is often the SFI teachers that refer them on to Bazar, and more often than not it is due to stagnation in the language learning process (ibid.). One of the interviewees, who had very limited knowledge of reading or writing upon coming to Sweden, expressed her willingness and desire to learn Swedish faster by practicing the language more:

$$
\begin{aligned}
& \text { "In SFI, we learnt a bit, but with a train- } \\
& \text { eeship we could learn more, they told us. } \\
& \text { At Bazar we would have the opportunity } \\
& \text { to learnt lots. It's because we would } \\
& \text { practice more, as it isn't just reading } \\
& \text { and writing, but talking Swedish. My } \\
& \text { friend and I decided that: yes, we want } \\
& \text { to try it! And the next week, we were } \\
& \text { here." } \\
& \text { - Interview } Z, \text { female from the } \\
& \text { Middle East. }
\end{aligned}
$$

Her willingness and enthusiasm to take on a new challenge is clear. Arriving in Sweden as illiterate and recognising her own ability to learn the language faster by seeing and doing, she realised her opportunity for creating new avenues for her own future. The language opens doors to understanding society, and its customs, and it breaks down the barriers for being a part of a new country. As the interviewee said:

$$
\begin{aligned}
& \text { "Everything is fine now. I understand } \\
& \text { more, I understand more when I am out } \\
& \text { and about people. I used to only stay at } \\
& \text { home, and I couldn't experience what } \\
& \text { society was like [here]. But it is all good } \\
& \text { now [...] It is good that women and men } \\
& \text { work, whether it is together or separate- } \\
& \text { ly. It is good that women work. Women } \\
& \text { should be allowed to experience and } \\
& \text { understand society [...] I think I would } \\
& \text { understand less if I didn't have a job." } \\
& \text { - Interview } Z \text {, female from the }
\end{aligned}
$$

Middle East.

Being in a traineeship through Bazar, the interviewee expressed that she had become more 
aware of the overall benefits of participating in a program, bridging learning a language with a better understanding of society, and the opportunity and benefits of building a social network.

\section{Creating Social Networks: Women and work}

Reaching out and getting newly arrived women on board programmes like Bazar is a proven challenge (Maria Karlsson, interview 5. December 2017). The role of social networks amongst the women themselves is important and becomes an important tool for encouraging their peers to participate (Interview Programme Manager, 2017). Established networks of locals working in natural meeting spaces such as the local churches and doctor's wards, play a key role in reaching out to these women and help them to enter Bazar, Esperanza, SFI and the like. Established contact with the native population is also reported to have an impact on the chances of entering the labour force (Bevelander and Pendakur, 2014).

There is however, still a barrier to entry, evident in the social anxiety and resistance often displayed by the women when first brought to Bazar:

\footnotetext{
"When I first came to Bazar, I was very anxious. I didn't want to try anything. But then [manager] and the other women were very nice to me, and spoke to me slowly and clearly. And now I regard Bazar as my family. Everybody is very kind."

- Interview $X$, female from the Middle East.
}

Realising the importance of meeting other women in the same situation and creating a social network, these local 'key holders' open up the initial doors to finding that safe space to learning Swedish and help women to find these key networks that aid their transitions into Swedish society.

Finding work that makes the women happy and content, whilst providing them with a job that is meaningful, is one the main objectives at Bazar. Baking and cooking is often part of their skillset upon entering Sweden, and Bazar attempts to further these skills by finding suitable employment in kitchens and cafés. Additionally, Bazar enables the women to think bigger and more long term. This was expressed by one of the interviewees:

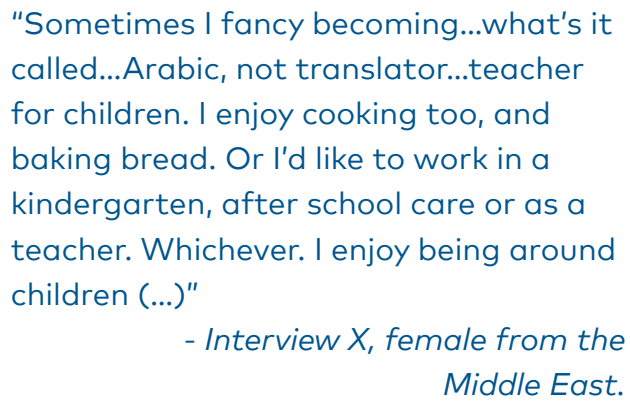

Constantly meeting women who are working such as e.g. the staff at Bazar or at the Public Employment Agency, may help ease the transition to understanding the Swedish way of life. Additionally, after being around Swedish women and having built up the trust necessary the newly arrived women feel more at ease to ask questions about gender roles in Sweden and the way families and society are run. The manager explains:

\footnotetext{
"They constantly meet women who are working. And we talk about it too; how it is in our homes [...] We tell them how it's been. How my husband has always worked, but how he has always helped with the children. They have so many questions [...] but you can tell they understand."
}

- Interview Programme Manager.

Moreover, it was suggested that seeing other Muslim women working at e.g. the Public Employment Agency may be inspiring.
"We are currently working with a Mus- lim woman at the Public Employments Agency. She wears a hijab (...), [and] she's got a university degree. [She] is a fantastic role model. It shows that you can work at the Public Employments Of- fice and still hold on to your faith."
- Interview Programme Manager.

Being allowed to gradually integrate and adopt the Swedish way of living, at their own pace whilst surrounded by other women in the same situation or who has been through the same situation, may greatly help the newly arrived women to overcome preconceived understandings of their roles in society at large. 
The role of culture, tradition and a female community

Integrating into a new society is a complex undertaking. Considering the women at Bazar, this is heavily reliant on the existence of support networks, including both peer and family support. From the interviews, it became clear that the greatest impact on the women social integration comes from peer-to-peer interaction, whilst the support from their families help break down barriers that often are associated with the traditional roles of women in their countries of birth. The role of culture and tradition still stands strong, but the realisation that it is possible to hold on to certain traditions whilst letting go of others is necessary in order to move forward, is present.

\section{Support at home}

The support system at home play an important part in integration. Additionally, there are some discernible differences between refugees arriving from different Middle Eastern and African countries, such as Somalia and Afghanistan. Bazar's manager is aware of the challenges of women that are stuck in the traditional patterns of their home countries, where women often are behaving according to the will of their husbands and sons. This was confirmed by the assistant, who said:

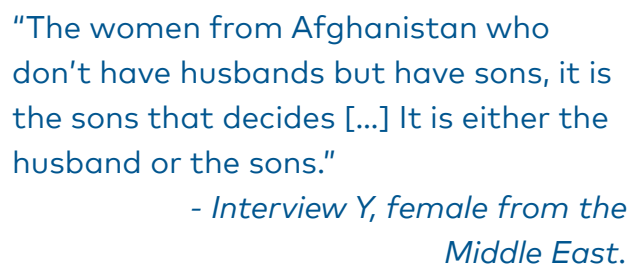

With time and participation in the Bazar programme, their mind set started to change, though some of these women arrived in Sweden with a seemingly strong sense of family hierarchies and the role of the mother:

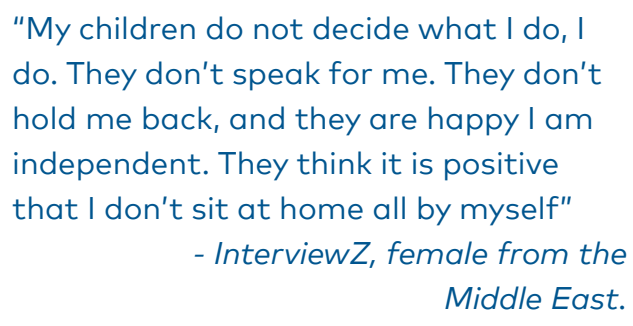

However, the attitudes towards gender roles are firmly ingrained in most of the newly arrived wom- en's understanding of Swedish society. According to Bazar's manager, the refugees and immigrant women are meeting different gender role expectations than they are accustomed to in their country of origin. Often, the women are to stay at home with the children, whilst the men are working. Moreover, because of this focus on the husband's job and prospects, the women had less of a focus on their own path to partaking in Swedish society. The main focus had, up and till their participation in Bazar, been to take care of their families and households. The expectations towards women in Swedish society can be very different from that of which they are familiar with. These cultural differences are addressed through their participation in Bazar, where they familiarise themselves with Swedish society.

One of the women interviewed said that upon their arrival in Sweden, she was trapped by feeling "miserable and unhappy" and "spent most days crying and worrying about her parents' situation in a war-torn Iraq", whilst looking after their children. Her husband, however, encouraged her to go outside and get to know the people and the culture in Sweden:

$$
\begin{aligned}
& \text { "My husband told me every day to go to } \\
& \text { SFI, but I said: 'no, no, no! I don't want } \\
& \text { to.' There were great difficulties in Iraq, } \\
& \text { and my mum and dad were there, in } \\
& \text { Mosul. I just cried and cried. But my hus- } \\
& \text { band said 'no, SFI is good, you cannot } \\
& \text { stay at home alone and cry.' And after } \\
& 4 \text { years, I'm finally in SFI, studying [...] } \\
& \text { Now I ask myself: Why were you sitting } \\
& \text { around for } 4 \text { years? I ask myself that } \\
& \text { every day!" } \\
& \quad-\text { Interview } X \text {, female from the } \\
& \text { Middle East. }
\end{aligned}
$$

This supporting attitude was also reported by a woman whose son was encouraging her to go outside and have a look around. It is thus not always an active prevention to enter the labour market from the family aspect, but often the women themselves who conform to the culturally contingent gender roles of their respective countries:

\footnotetext{
"I didn't want to do traineeships of any kind. In Arabic countries one doesn't like to be around a lot of people, and neither do I [...] This is my first traineeship. Only
} 
women. I didn't want to be around men. My husband asked me: 'why only women?' And yes, why? It isn't really a problem at all! So, I've told [the manager] that it isn't an issue anymore. I'll give it a go. I might be a bit scared. But I'll try." - Interview $X$, female from the Middle East.

Furthermore, this is often due to the level of education of the husbands in question, or indeed the realisation that the income the women have benefits the whole family. The encouragement to enter the labour market tend to come from husbands and families with higher degrees of education, and who understands the benefits of having an independent wife, was mentioned as one of the keys to successful integration by one of the interviewees. However, it was also evident that there was a difference between seeing the benefit of having an independent wife and having an extra income to the household.

The side effect of having been encouraged to learn Swedish and get a job, to receive support funds, and later a salary, was less desirable for one of the interviewee's ex-husbands. Slowly adopting her new country and culture, the interviewee described how she became increasingly independent from her husband and got the courage to remove herself from a situation where she was bound by expectations and traditional gender roles. She spoke of the inspiration she got from her colleagues, to become a stronger individual by learning. Her independence was hard-won, but she recognises the importance of taking a stance:

"[...] It is the husband that decides. Not the wife. That is why I wanted to know more, I wanted to become stronger. If I stayed at home all the time whilst living in Sweden, I would never have become this strong. I wouldn't have learnt. And when I was out amongst people, my friends told me how they live and how they decide (...) If you stay at home you would never learn anything."

- Interview $Y$, female from the Middle East.

Following from the interviews, it is evident that situation for women arriving as refugees or as immigrants along their husbands face a complex in- troduction to Swedish life and society and it needs to be adequately addressed. Equipping them with self-help tools in addition to language skills is an important measure that Bazar has put in place. Bazar as an arena to develop language skills, practical skills such as reading, writing and mathematics, and the ability to create a social network, is empowering immigrant women.

\section{Peer support}

At other times, it is important when their peers are challenging their traditional understanding of society. This is particularly important when it comes to overcoming barriers to working in Sweden, or to allow their children a different upbringing from their own. The manager recalls a situation when working with non-halal ${ }^{6}$ meats:

$$
\begin{aligned}
& \text { "[One of the women] did not want to } \\
& \text { work with meat that was not halal, but } \\
& \text { we were wearing food-grade gloves. She } \\
& \text { still did not want to touch it. So, we were } \\
& \text { about to call someone else when one of } \\
& \text { the other Muslim women told her that } \\
& \text { 'if you wanted a job in Sweden, you have } \\
& \text { to work with non-halal meats wearing } \\
& \text { gloves. If I couldn't make the salami and } \\
& \text { ham sandwiches that I make daily with } \\
& \text { gloves, then I shouldn't have a job!" } \\
& \text { - Interview Programme Manager. }
\end{aligned}
$$

Another example is a discussion between two of the Bazar-women regarding raising children and, particularly, girls:

"[One of the women] was not allowing their female children to play with video games or anything else. K protested and said "when I was a child and played with balls and dolls, I was married to a man. I never got to finish playing. Surely, girls should be allowed to play video games.' It was just...wow. That came from the right person"

$$
\text { - Interview Programme Manager. }
$$


This realisation by the Bazar-women is significant in two ways. First, following the example of their peers of the same faith may have a greater impact on these women's world view, than the managers at the centre. Having a similar cultural and religious background, they show that it is possible to remain a person of faith whilst taking part in the society in which they are now living. Moreover, it demonstrates the clout and legitimacy this background carries in influencing others in a similar situation. Second, it shows that certain traditions are subject to change, and that traditions need to be dynamic in meeting with new societies; that rigid traditional world-views often are individually held, and not universally held understandings.

\section{Empowerment through self-confidence}

Equipping women with the ability to take charge of their own lives and allow for space of their own greatly helps their social networks, their confidence when amongst Swedish people and in their daily lives at home. The programme manager has noticed a great change in the women coming to Bazar, especially with regards to the women's "self-confidence and their outwardly focus". Moving away from merely focusing on their children and husbands, they are now realising that there are possibilities for themselves as individuals. This observation is backed by one the interviewees, who said the following:

\footnotetext{
"Now I don't want to be at home, I want to be out and at work all week. I'm home on Saturdays and Sundays and do the housework then, but I'm gone again come Monday morning!"

- Interview Z, female from the Middle East.
}

One of the women interviewed told us that she had been very resistant to take part in Swedish society and that she additionally had been scared to go out and meet the people of her new country. However, this has slowly changed since joining the Bazar programme:

\footnotetext{
"I used to call my husband if I needed salt for the food, and he used to tell me to get it myself. I didn't want to, so he would bring me the salt. Now, there's no problem. I just say: your card and code,
}

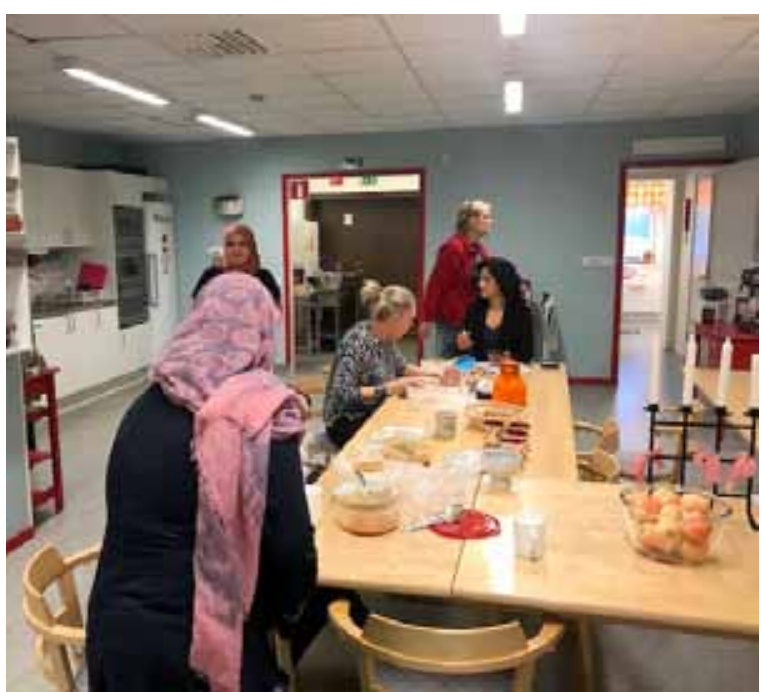

In Bazar, participants and programme leaders work together on different assignments. Source: Hjördís Rut Sigurjónsdóttir

$$
\begin{aligned}
& \text { please! And 'Good bye'. So now he only } \\
& \text { buys clothes for our children. Not for me. } \\
& \text { I want long dresses. And I get the food } \\
& \text { as well. It feels good. Sometimes my } \\
& \text { husband jokes and says: you should stay } \\
& \text { at home. I'd also like some money left of } \\
& \text { the card!" } \\
& \text { - Interview X, female from the } \\
& \text { Middle East. }
\end{aligned}
$$

Rapidly learning the language, she now feels confident enough to undertake daily tasks, such as grocery and clothes shopping for herself. She ended the interview by stating that Bazar had equipped her to become brave enough to be part of Swedish society on her own terms.

\section{Findings}

Perceived barriers, whether personal or structural, evidently play a role in the integration of the women that stand farther away from the labour market. These include e.g. the language, traditional gender roles, and remnants of customs and traditions in their home countries. Coupled with a lack of self-confidence in terms of becoming a part of the labour force and furthermore, the insecurity that follows when adopting a new society, integrating into Swedish society requires more than language skills. Empowering women through building their self-confidence in relation to Swedish society is perhaps one of the main achievements, and could be seen as the main, but underlying, objective of the Bazar programme. Being able 
to take change of their own lives by slowly being exposed to a different way of partaking in society, these women are on their way to becoming an asset to the local economy in Luleå, and moreover: an important statement, demonstrating to policy makers and newly arrived refugee and immigrant women that there are possibilities and opportunities for everyone.

\subsection{Discussion and Conclusion}

As this part of the study aims to identify existing policies and practices made to improve labour market integration for immigrant women in Luleå, this implies a necessity to identify and analyse both the success factors and the present challenges. This study has focused on the experiences of different actors in the labour market landscape, who have participated or worked with these programs in one way or another.

Although immigration to Luleå has increased in recent years, the level of immigration has not been as large as it has been, on average in Sweden. Labour shortage is a persistent feature of the local labour market, and Luleå has until recently been fighting population decline.

The authorities, as well as employers seeking competences and a work force, are aware of the importance of increasing participation by including those currently standing outside of the labour market. Policies are in place and the Swedish Public Employment Service is responsible for providing labour market measures to ease people transition to the labour market, immigrants as well as others that are outside the labour market.

When conducting interviews for this study, a few things emerged that needs to be continuously improved. Moreover, recognising the complexity of labour market integration as an integral part to social integration is important.

\section{Swedish for wider integration}

Learning the Swedish language to ensure full participation in Swedish society was strongly supported in this study. According to the interviewees, the lack of Swedish language skills was an inhibitor to accessing the labour market. In turn, this would limit their access to general society, often leading to isolation, regardless of the women's English language skills. Although relative fluency in English diminished the levels of isolation, Swedish is the dominant language, and the interviewees voiced their dependency on others to get access to e.g. written information, and to navigate the information flows.

The level of language knowledge required to become eligible for the labour market is unclear. This was reflected in the conversations with the interviewees and is in line with Aure (2013). In her report, it was highlighted that the language requirements set by employers is often unnecessarily high in comparison to what is needed, and additionally, what can be learned whilst being employed. According to Harbo et al's working paper (2017), it takes more than two years to master a Nordic language. To speed up integration and inclusion, it is therefore important to continue the language learning whilst being part of the workforce. Learning a new language is process, a process where employers can get more engaged by making the demands more reasonable and give space for development in the workplace.

The programmes considered for this study provides a dual mechanism for integration, by teaching Swedish and preparing the participants for the Swedish labour market. The women in Korta Vägen, with many years of education, get an intensive language learning that is also aimed at their professional qualifications, and prepares them fast for labour market participation. In Bazar, the participants prepare foods for the café operated by the programme whilst learning the language, and practicalities of Swedish society and culture. Later in the process they have the opportunity to work in Bazar's own café, where they are able to gain experience and move closer to the general labour market.

Getting a foot onto the labour market, get references for their work and gain experiences that Swedish employers can relate to, and find easier to measure is a very important factor in both Korta Vägen and Bazar. Through Korta Vägen internships are provided by the employees' networks, as well as being secured due to the reputation the programme has built in recent years as a reliable source of highly skilled potential employees. In this way the programme manages to bridge the gap between immigrants that often have limited social network, and the local labour market. Additionally, the participants may start building their personal professional networks in the duration of the internships, whilst proving their ability to the employers and for themselves. In turn, this positive experience allows the programme participants to gain confidence and get to know the Swedish la- 
bour market, as well as the everyday life in their host society.

\section{Learning Swedish}

There are different approaches used for language teaching in the two programmes considered in this study. Both respond to the participants educational backgrounds. Korta Vägen is formatted to fit people with higher education, whilst Bazar is aimed at women far away from the labour market with lower levels of education.

Before starting in the programme, all participants will have studied Swedish at Swedish For Immigrants (SFI) for varying lengths of time. It was noted that for most programme participants, the language learning progression was more readily experienced when in the respective programmes. This might be because the programmes respond better to their individual needs. In a teaching environment where the level and method better fit the educational background, the women are provided a space where they can gain confidence in speaking the language.

The women in Bazar have no or little education and some are illiterate. In the programme they get the opportunity to learn the language in a different way than through a traditional classroom teaching. Not only are they taught using a suitable and a more practically oriented method, but the language learning takes place in a safe learning environment. This contributes to increasing self-confidence needed to speak Swedish, and for moving beyond this safe space and into Swedish society and life.

According to the participants in both groups, their self-confidence grew in the programmes and better language skills also promoted confidence outside the classroom. Language learning tailored to the students proves to be a success factor for both groups in this study.

\section{The Programme Factor: Empowerment and Social Networks}

Empowerment through the programmes is clearly reflected in the interviews. Those with lower levels of education describe how they now feel more confident in approaching their host society. Especially with regards to Bazar, it is empowering and incentivising women who have traditionally been standing far away from the labour market, and who possibly never envisioned themselves as part of the labour force, to consider alternative futures.
Others described how their had gained confidence and increased independence by gaining language skills, understanding the local labour market better through teaching and internships, as well as gaining a wider social network and the support given by their peers in the program.

Establishing a social network is important for entering the labour market. Gaining access to the Scandinavian labour market often happens through professional and social networks. Following from statistics provided by the Swedish Employment Service, approximately $70 \%$ of unemployed people who eventually found work did so via informal channels or networks. Only $16 \%$ found a job using the formal channels (Swedish Public Employment Service, 2017a). In another study, 70\% of foreign academics say that lack of networks was the greatest obstacle to finding a well-matched job in Sweden (Västra Götalands Region, 2014:5).

\section{Achievements and challenges}

Not adequately addressed by this study is the group of women with both education and experience that fall between these groups, and who are facing different challenges that are not covered in full in this study. One of the groups that might need more attention in terms of labour market integration are those who have not managed to complete their studies before leaving country of origin. It is relatively difficult to get foreign education evaluated by the Swedish educational system, although this is decidedly country-dependent. The risk is however that attained education from the refugee or asylum seeker's country of origin may be lost. Moreover, the general motivation for retaking studies after years already spent in the education system might be significantly impacted on, as expressed by interviewees in this study. It is important to recognise that this is not only a loss for the individuals themselves, but also a loss of potentially valuable knowledge and human resources for the host country, that is unable to take advantage of these individual's existing skills and experiences.

It was evident in both programmes that the desired results will not be realised without determined personal efforts and motivation. The programmes need to respond to this and ensure positive attitudes towards tackling the impending challenging steps that involve entering a new labour market. To make the most of the programme and the tools provided, motivation, or indeed being 
responsive towards being motivated by others attest to being highly important for the participants' respective success. How determined individuals are in taking on that challenge varies, but it was evident that the collective power of a group in facing and overcoming similar hurdles plays an important role in inspiring and motivating each other. This was observed both in Korta Vägen and Bazar.

Although the respective programmes are successfully achieving their desired goals, it should be noted that these programmes only serve as one part of the solution, and is not, in and by itself, a so-called silver bullet.

\section{Outreach for integration}

Coming to understand the Swedish society is the key to unlock motivation and to envision one's place and possible paths in the host society. Communication for increased cultural understanding through the participation and inclusiveness in programmes, need to go hand in hand. As it can be challenging to settle in a new country, to learn a new language, and get acquainted with a new culture, the programmes need to continue to account for the complexity of labour market integration. The nature of the Swedish labour market is firmly embedded in a wider social system that is not necessarily readily accessible for newcomers to Sweden.

Integration in Sweden is described and acted on as a two-way process, whereby the majority of the population and the various minorities present in Swedish society, are in a constant process of mutual adaption (Hagelund and Kavli, 2017; Karlsdóttir et al., 2017). In this process, discrimination may play a restrictive underlying factor for further labour market access and subsequently a factor reducing motivation. In this case study, the employers interviewed were very positive towards cultural differences and the diversity that it brings. However, it was evident that they knew that not everyone held the same attitude towards immigration. The participants had both positive and negative experiences from inclusion efforts in their workplaces. This may indicate that the employers themselves should take greater responsibility in communicating the importance and necessity of the skill and knowledge brought to the companies by the immigrant workers, as essential to their financial turnover and economic stability. Moreover, the employers should play a greater role in facilitating social inclusion in the work place. This in turn may change prejudices against immigration observed in society at large.

\section{Structural barriers}

Following from the interviews, it became evident that the current system and the possibilities within it are not wholly accessible for all. Although information is cascaded by the officers in the Public Employment Service to ensure that their clients, the immigrants, have the best possible opportunities offered to them, exploring these opportunities on in their own time was expressed as being a significant challenge. Navigating the system without help from their personal officer is considered difficult.

It is also important to consider to what degree the responsibility of integration is placed on either actor in the system, whether it is the authorities or the individual immigrant. The dynamic observed in the programmes places a lot of emphasis on the immigrant to ensure their own integration, though this may continue to be challenging in meeting women of different cultural background. This is repeated in Fernandes' study on introduction programmes in the Scandinavian countries, she argues that introduction programmes often attempt to 'transform the individuals', without recognising the structural barriers that need to be overcome. The focus tends to lie on the individual immigrant/refugee's own responsibilities for integration, rather than considering the underlying social structures that are inhibiting their full integration at the outset Fernandes, 2015). Thus, striking the balance between social integration as well as labour market integration becomes important. It is also an imperative that the personal officers recognise the different cultural understanding this group of people needs for true integration.

Individually perceived barriers evidently play a role in the integration of women standing farther away from the labour market, such as traditional gender roles, and remnants of customs and traditions in their home countries. Coupled with a lack of self-confidence in terms of becoming a part of the labour force and furthermore, the insecurity that follows when adopting a new society, integrating into Swedish society requires more than language skills. Empowering women through building their self-confidence in relation to Swedish society is perhaps one of the main achievements, and could perceived as the main, but underlying, objective of the Bazar programme. Before taking part of Bazar, it is important that communication is clear and open, and that the women are met in their own 'social language'. 



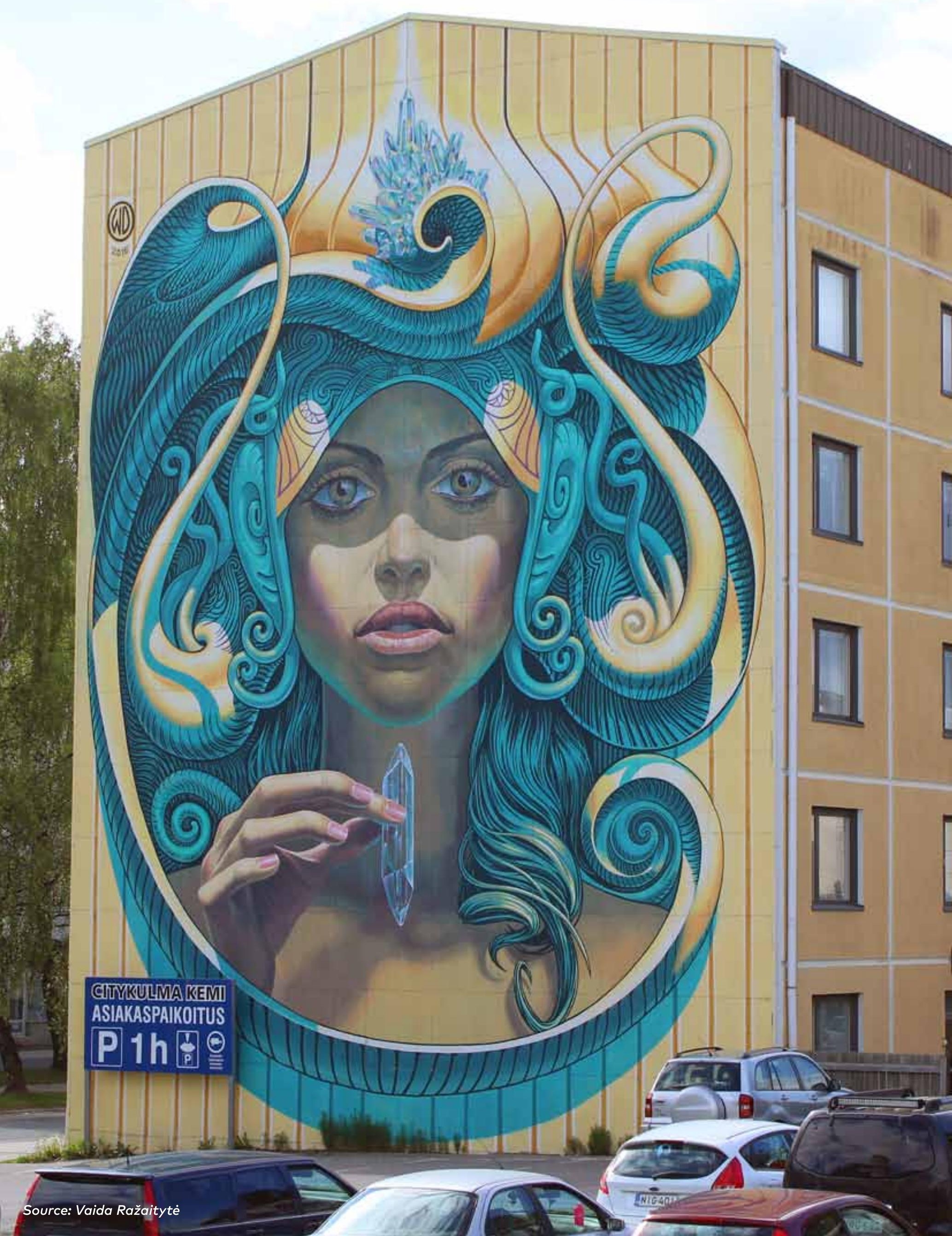




\section{Finnish case study: Enhancing labour market opportunity for immigrant women in Finnish Lapland}

\subsection{Immigration and the labour market in Finland after $\mathbf{2 0 0 0}$}

The number of immigrants living in Finland has been steadily on the rise for the past decade; in 1991, the number of immigrants (persons of foreign background) was less than 50,000, increasing to approximately 300,000 in 2016 (Statistics Finland, 2017). About 34,905 persons moved to Finland in 2016; 21\% more than 2015 (Statistics Finland, 2017). According to Finnish statistics, the percent of overall immigration was $6.0 \%$ in 2016 (ibid.). The reason for migrating to Finland is not only to find jobs, but also for bettering the immigrants' lives. Many of the immigrants to Finland arrive as refugees, whilst others are seeking asylum.

In 2016, the government published an action plan that outlines the key objectives of integration, which includes employment, good relations and internal security of migrants (Statistics Finland, 2017). It also focuses on measures, responsibilities, and resources for proper integration in Finland. Migrants coming to Finland as refugees and asylum seekers were not seen as active participants in the long-term economic prosperity of the country but rather as jobseekers in the labour market. Supporting the integration of immigrants, the government adopted an integration program for the period of 2016-2019, which was approved in September 2016. There are four priority areas: 1) Using the cultural strengths of immigrants to promote Finnish innovation, 2) Enhancing integration through cross-sectoral measures, 3) Increasing cooperation between the State and municipalities in the reception of beneficiaries of international protection, and 4) promote discussions nation-wide regarding humanity, to combat racism. To implement these policies, the Finnish government has introduced nearly 70 measures (Statistics Finland, 2017). Since migration also brings talent from all over the world, migration is being seen as an op- portunity for Finland to create new jobs, and spur entrepreneurship and innovation (Ministry of Economic affairs and Employment, 2016).

In 2016, the unemployment rate among immigrants was at $17 \%$, of which unemployed EUborn represented $9.6 \%$, and non-EU born $22 \%$. The unemployment rate among non- EU born women was $25.8 \%$. The figure combined with both EU and non-EU born immigrant women was 19\% unemployment (Eurostat, 2016). A survey among immigrants showed that every tenth immigrant with foreign born backgrounds were unemployed in 2014, of which women with foreign backgrounds performed much poorer than their Finnish counterparts, with unemployment rates at $10 \%$ and $6 \%$, respectively (Statistic Finland, 2015). In contrast, the unemployment rate among Finnish-born people was $7.6 \%$, in which unemployment rate among Finnish men is $8.2 \%$ and Finnish women, $7.0 \%$ (ibid.). Immigrant women have less access to labour market than Finnish women and are under-represented in the Finnish labour market. They rarely hold management positions and earn less than their male counterparts and opportunities for immigrant women in the labour market are very limited (Chang and Holm, 2017). Additionally, new research shows that immigrant women, refugee women and Asians are the most vulnerable in the labour market in Finland (Kangaspunta, 2018). According to a previous study, $65 \%$ of women who have been living in Finland less than 5 years are unemployed (Pehkonen, 2006). According to the OECD report (2018), immigrant women who are from Iraq, Thailand, Somalia, Vietnam, Afghanistan and India are below the average rate in employment services. The employment gap of this group of immigrant women are higher than many other immigrant women e.g. from Russia, Estonia, Sweden etc.

The chance of obtaining a new job or get access to the labour market have been decreasing among 
immigrant women in recent years (Kangaspunta, 2018; OECD, 2018). Their previous work experience is not always recognised. Finding a job according to the educational background of immigrants is also challenging, and many immigrants remain unemployed due to discrimination and social exclusion (FOLO, 2018). More often than not, employers do not place trust in credentials from outside Europe, which accentuates the issue (Yeasmin, 2012). Western immigrant women and their credentials are more likely to be acknowledged by the Finnish employers and facilitate labour market integration of particular groups of women (Jakkola and Reuter, 2007). Some refugee women that lack an educational background from their country of origin need several years to get access to the labour market. According to research done by the Finnish Ministry of Foreign Affairs, 35\% of jobs are off limits for immigrant. Other research also states that an immigrant's foreign credentials and education, or even their experiences are not recognised in the hiring process. This is often referred to as work racialisation (Shalla and Clement, 2007). According to the migration integration policy index, Finland has a high "brain-waste" rate which is double that of non-EU women in comparison to native women and non-EU men (MIPEX, 2015). Non-professional jobs like cleaning, driving cabs, distributing newspapers are available for immigrants.

Before the recent crisis, after a sudden flow of asylum seekers in 2015, the lack of knowledge of the local language was seen as a big concern for securing a job in Finland. There are also major employment differences among nationalities of immigrants. By 2013, however, these employment variations among groups had largely disappeared and the employment rates of all the different nationalities had stabilised at 52-58\% (Sarvimäki, 2015). However, in recent years after the asylum flows in 2015, the gap has become comparatively higher (Kangaspunta, 2018). Moreover, the gap between the immigrants and the native populations in employment and earnings has decreased over time, but the gap between native women and immigrant women has remained modest (Sarvimäki, 2015). The employment gap between immigrant and native women is substantially larger among those who have children under 18 than among those without. (OECD, 2018). "Even after five years in Finland, migrant women with children see employment rates that trail 47 percentage points behind those of native-born women with children" (ibid.) The income gap between immigrant men and women from middle-East and Africa are also relatively high (Eronen et al., 2014).

Lately, discrimination of foreign and immigrant employees is a common factor among Finnish companies, and refugees and asylum seekers are in the most disadvantaged group in addition to language barriers. For instance, the unemployment rate among Somalis, Iraqis and Afghans has remained lower (OECD, 2018). To overcome this challenge, a series of events e.g. thematic FOLO forums, several speed dating events where immigrant employees encounter employers have been organised in 2017 by FOLO project to incentivise companies to employ immigrants. Younger employers are more positive than older employers towards hiring immigrants, and women employers tend to be more open to employ immigrants than men.

The unemployment rate among immigrants also varies between the regions and the metropolitan areas in Finland. Employment rates among immigrants also varies in the cities. Bigger cities tend to be generally more receptive to immigrant workers compared to smaller cities (Jaakkola, 2009; Open Society Foundation, 2013). General feelings of interviewees, Immigrants are often not considered in regional development policies.

There are many factors leading to unemployment or underemployment of immigrants. Women are struggling to integrate; many are inactive in labour market, are staying at home, (OECD, 2018) which also increases risks of being marginalised. Immigrant women are usually eligible for the Child Home Care Allowance which may attract them to staying at home than engaging them in job -training or paid employment.

For example, integration pressure, lack of adequate Finnish language skills, unclear demands for Finnish language skills by employers, lack of social networks and contacts, which in turn influence on the immigrants' ability to get access to information for finding jobs partly related to their education or other local experiences (Shimilova and Cai, 2013). Therefore, getting access to the labour market varies on many micro subjective and objective factors along with many other macro subjective to objective factors. Other issues are concentrated around ethnic discrimination, lack of information, poor attitudes from Finns etc. (Mutuku, 2017). Immigrants are not usually involved in the political arena and decision-making process 
which is important to promote a better fair representation in the policy making phases (Karus and Koivisto, 2015) in Lapland. Therefore, they cannot influence in policy making. In bigger cities like Helsinki, many immigrants are involved with political arena, thus the labour market discourses of employability and overall integration get positive responses to some extent. Moreover, poor political integration is generally the reason for the inability of many immigrants to be socially included in Finnish society (Forsander, 2008).

General description of the municipality Rovaniemi, LaplandLapland is a sparsely populated area located in the north of Finland, and Rovaniemi is the largest town in and the regional capital. The population has been stable between 2008-2015, and the immigrant population has grown from 2033 people in 2005 to 4013 in 2017 (Statistics Finland, 2017; Lapland Centre for Economic Development, Transport and Environment, 2017).

The majority of immigrants in Rovaniemi are refugees. The other immigrant population is usually students, asylum seekers, or spouses of Finnish people migrating to the city. The five most common nationalities living in Rovaniemi apart from the native Finnish people are Russians, Swedes, Iraqis, Myanmars and Somalis (Yeasmin, 2012). Of the Russian population, the most cited reasons for migrating to Rovaniemi were marriage, business and employment opportunities, and education. The number of immigrants is $2.2 \%$ of the total population of Lapland (Lapland Centre for Economic Development, Transportation and Environment, 2017).

With a total of almost 60000 inhabitants in 2017, Rovaniemi is also the home of $1592 \mathrm{im}$ migrants (Lapland Centre of Economic development, Transportation and Environment, 2017). Representing $5 \%$ of the population, the town's immigrant population originate primarily from Russia, Palestine, Syria, Somalia, Myanmar, Germany, Thailand, Estonia and Sweden. The unemployment rate among immigrants is $27.5 \%$ in Rovaniemi and in Lapland as a whole is $30.4 \%$. The access to the labour market is hard for both skilled and unskilled immigrants, since the unemployment rates amongst Finns in the region is also high and are competing in the same labour market as the immigrants. There are job opportunities in the tourism and service sectors, but these are mainly seasonal. These seasonal jobs are mainly lower threshold

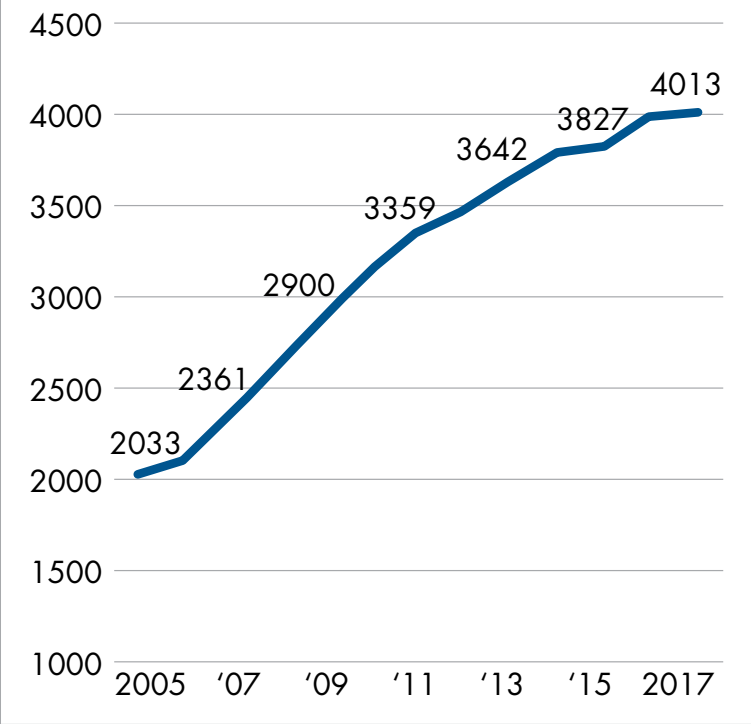

Figure 1: Immigrant population in Lapland. Data source: Lapin ELY- Keskus (Lapland centre of economic development, transport and the environment, 2017)

jobs; therefore, immigrants view social welfare benefits as more advantageous. In December 2017, the number of registered jobseekers' immigrants in Rovaniemi were 507, and of these 192 have been fully unemployed (ibid.).

The municipality of Rovaniemi recently assumed the responsibility for providing aid to longterm unemployed immigrants, ensuring necessary support for the job seeking process. This is a service provided both to Finnish people and to immigrants alike, although the nature of these jobs may vary. Immigrants tend to get more low-skilled job offers than their Finnish counterparts (Yeasmin, 2017). There is also a learning centre in Rovaniemi promoting adult education that offers different support measures to the immigrants, but these initiativess are temporary, and project based.

\subsection{The relationship between language knowledge and the labour market}

At least six immigrant women participating in this study have a good command of the Finnish language. The possibilities for language learning in Northern Finland is available for all immigrants, however sometimes, they have to queve for 2-3 months before being admitted to language learning courses offered by the government. The language learning courses are part of the integration services. The Rovalan Settlement Ry and Airffman institutes offer language courses to registered jobseekers in the local employment office. Basic com- 
puter skills, language lessons, leisure activities for practicing the language, and information regarding working life in Finland are part of the services provided by the aforementioned programmes. These activities not only help the immigrants' language skills, but it also helps emphasising the individual's potential in Finnish society. The Rovalan Settlement Ry and Airffman institutions offer integration programs that last longer than one and half years and includes internships and training opportunities in work places for certain periods of time. This is an opportunity to learn about Finnish working life in practice and can discover the hidden norms of a working place. Alongside this, it also supports immigrants to learn and practice Finnish language and enhance their vocabulary on special trade terminology(s). This service is procured by the Lapland ELY-Centre. This is a part of early integration service emphasis on language alongside, civic orientation with a special focus on labour market orientation. ELY centre periodically places the provision of integration training out to tender. Normally, many different educational institutions can submit applications for providing the integration training by their institutions. However, Rovalan Settlement office and Airffman has good and long reputation in providing integration training.

There are some temporary projects implemented by the municipality of Rovaniemi, the University of Lapland, the University of Applied Science Lapland, various vocational training institutes etc. as well. These institutions also provide trade related terminologies in Finnish, which support immigrants to increase and enrich their vocabulary based on their professional background, building on the basic language skills learned at either the Rovala or Airffmann institute. Some of the other projects provide supplementary education alongside the Finnish language courses, so that the immigrants are able to develop their professional education as well as their language skills at the same time.

There are also other non-governmental multicultural organisations that support immigrant groups queuing for language learning classes at the employment services. These organisations also support some basic Finnish language training for free. These non-governmental organisations have been supported either by the municipality or other European, as well as national funding schemes. One of these organisations is MONINET supported by the Rovala Settlement Ry and Rovaniemi municipality alongside STEA - a national funding scheme. Immigrants who joined the program earlier and have obtained a medium level of the Finnish language, usually help the newcomers in MONINET. There are also Finnish project workers providing support throughout the period they are in the MONINET- programme.

Immigrants who are very slow at developing their language, have no educational background or are illiterate enlist at evening schools free of charge. Sometimes the municipality also fund the language courses in the evening schools for adult learners, and the participants can participate and take other subjects alongside Finnish language. The duration of the participation in the evening schools depends on the needs of the respective immigrant. Some refugee women aged 40-60 years old from Myanmar, Afghanistan, Syria or Pakistan without any formal education would normally be slower than other groups. This group is also the most marginalised group, as they often lack the vocational skills needed to enter the labour market. They are first introduced to learning the language at either the Rovala or Airfman institute, before being transfered to the evening school. Due to these women's backgrounds, the Finnish government tries to incentivise this group of women to attempt to obtain a degree from vocational school where they are able to focus on developing their skills in areas such as baking, cooking, or sewing, or get the vocational education to become a day care nurse. However, these women tend to lack the motivation needed to be admitted to the vocational school, as their culture and circumstances often do not permit them to consider life-long learning as an option. This includes the idea that they are too old to be taught. Nevertheless, there are examples of women in this group that have started vocational training, with one year of preparatory Finnish language courses prior to commencing classes.

Those who arrived as international students and have not registered at the employment office, do not get offered a place at the 'language classes for integration', although there are some projects funded by different national and European funding schemes that support language teaching for student and international students to learn Finnish language from their own institutions. The local employment office in co-operation with the language training centres help individuals to find the appropriate courses and programs that suit them after the language training. This service is for free 


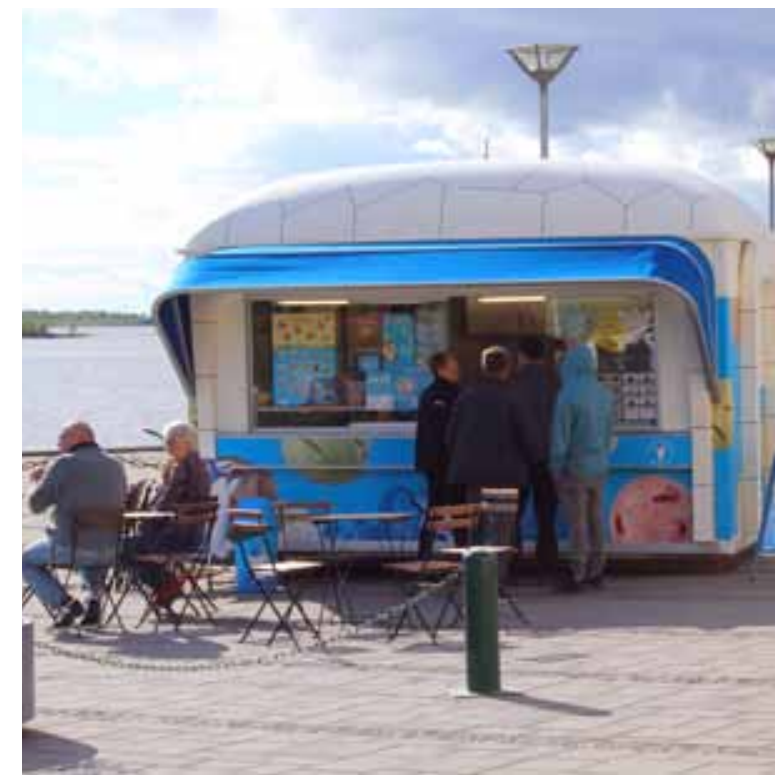

Source: Vaida Ražaitytè

and planned according to the individual integration path. All immigrants who are registered in employment office have an individual integration path based upon an initial settlement assessment. An initial assessment encompasses an initial interview, a test of language skills and an assessment of other previous skills.

\section{Language as a pre-requisite for employment}

Integration training which is a national program for all immigrants s seemingly an important part of integration in Finland for those who are seeking job at the time of arrival. (OECD,2018). During integration training, the immigrant can study Finnish or Swedish, and they are taught reading and writing skills if necessary based on the initial settlement assessment. For receiving unemployment benefits, it is potentially important to take part in initial assessment and participate in integration training (The Employment Office, n.d.). Integration training will also support civic, cultural and other skills that will ease whole integration process of immigrant to become part of Finnish society (The Employment Office, n.d.).

Eight of the women interviewees have taken one and half year of the above-mentioned language integration program at the Rovalan settlement or Airffman institution. Some expressed satisfaction with what they learned during the languages classes, while others highlighted the inconsistency between the teaching content and their individual level in Finnish. The participants stated that practicing the language is also important after ending the course. They do not have enough interaction with Finns for adequately practicing the language, therefore they usually forget the language or words after the integration program. Thus, they feel that the continuation of practicing the language through the work place or through social activities are relatively important after the language training classes have ended.

The language barrier is perceived both by employers and by immigrant women as a hindrance to find appropriate employment situations. One the one hand, Finnish employers often have prejudice and believe that immigrants do not speak Finnish sufficiently to be considered for a job (Interviewee III). On the other hand, although immigrant women feel that they lack the professional language skills, they have a good colloquial command of the Finnish language. However, employers demand and appreciate high levels of language proficiency of immigrant women, and fluency in communicative Finnish is often a requirement for many employers. One of the interviewees finds this a feeble excuse:

"Finnish language skills is lame excuses
for some Finnish employers to avoid
recruiting immigrants. Some of the jobs
do not demand fluent language profi-
ciency, only communication is enough
for those job types are still not offered
to immigrant, why? I think, employers
would like to take Finns or some other
EU or western people, they don't have
trust in our credentials or standards. But
it could also be the culture. We don't
belong from same culture [sic]. Maybe
they thought that they need lot of time
for our orientation in the working place,
since we are from different culture and
are different looking. It is easier for em-
ployer to recruit a Finn than immigrant."
Interview I

This example illustrates that immigrant women lack confidence in utilising their language skills and their potential to apply for jobs that fit their education. It also illustrates that they are deterred from applying because they believe that employers wouldn't consider their applications. However, lack of local language proficiency exclude immigrant even within their work place; both employers 
and immigrant women suspected that insufficient Finnish language proficiency segregate them from the majority group member in the work place, as exemplified below:

\begin{abstract}
"I have applied several jobs and I have Finnish credentials and speak Finnish, still it is difficult to get job. My partner is Finnish, I speak Finnish at home with partner. Still it is hard for me to get access to Lappish labour market."
\end{abstract}

\section{- Interview II}

\begin{abstract}
"People have the preconception that immigrant like us are not perfect for doing jobs and I have been in job training, in the first day my co-worker asked me whether I speak Finnish? Do I have any working experiences from my country of origin? Do women work in our country?"

- Interview III
\end{abstract}

Some employers feel that language is not a matter, like employers in the tourism sector are very flexible regarding language skills. But work in the tourism sector are seasonal and low-waged work and not attractive among women with family and responsibilities. Usually, these jobs also demand English language skills. Some of our respondents' lack English skills and it is predominantly students of European or western origin that work in this sector:

"I have completed vocational education
from Rovaniemi, but after completing
my education, I found that there are
no available jobs in my field of profes-
sion. For me, it is hard to change my
educational background at this age. So,
it would be quite useful if some author-
ity can address specific labour market
needs and navigate us accordingly ..."
- Interview I

Knowledge of Finnish and credentials from a Finnish educational institute are sometimes also not enough to secure appropriate employment for these women, since many Finnish people remain unemployed in Rovaniemi. General feeling among the interviewees that employers prioritise Finns rather than immigrants for their job openings. However, immigrant women who do not have any experiences from their country of origin lose their confidence level, and they lack determination to work. Some women also lack soft-skills e.g. communication skill, social skills etc. to deal with people. Their culture of origin could be considered an informal barrier for working.

\subsection{The integration in the labour market through internships}

\section{The structure of internships}

The internship program is usually funded by the employment office of Finland. It allows companies to accept interns without the financial obligation of the management otherwise required and alleviating the pressure of sustaining their working agreement for long-term employment. According to the women interviewees, most have been working as interns for some employer. Only one of the interviewees received an hourly based job as a result of the internship lasting a few months.

Acting as a bridge between employers and potential employees, the program does have the advantage of encouraging immigrant jobseekers and motivate them to apply for jobs, but the program also encourages employers to change their attitudes towards recruiting immigrant jobseekers. Employers need some interaction with immigrant jobseekers for social change and for developing their attitudes towards immigrants within the workplace; Finnish employers usually prefer to employ individuals with the same language and cultural understanding and may be hesitant to promise long-term employment to immigrants.

The employment office in Finland does not have regular outsourcing service in finding both employers and employees for internships is crucial. Usually, jobseekers must communicate with companies themselves in order to find internship opportunities, what is needed is therefore some long lasting and stable practice which includes common tools with regards to how to reach employers and ask for an internship. At the moment some projects mediate between employer and employees on a temporary basis. The support of the employment office is irregular as they are lacking sufficient resources regarding job mediation. The employment office meets with the individual interviewee, which is a very formal procedure and is limited to a timeframe. Some interviewees also reported that it can sometimes be challenging to reach employment officers. The 
employment office does not automatically offer an internship program to individuals which responds to individual needs or to the requests of companies and jobseekers to some extent. It is individual jobseekers who have to search his/her internship place and need to inform to employment office.

There are many different projects supporting immigrant jobseekers in the municipality of Rovaniemi. The municipality itself recently adopted some initiativess to support immigrant jobseekers. However, the immigrant women responded that what is missing are targeted programmes for immigrant women only as they have a different set of challenges, and special initiativess to implement measures that address these situations. Some of the interviewees in this study lack the stable approach of such special programs that wouldpromote employment in practice. For some of the aforementioned institutes, the objective of implementing a set of actions for helping these women, job training could also be effective for some of our interviewees who would like to improve their possibilities to participate in the job market. However, some of the interviewees feel that employers are exploiting their working hours as free labour through internships, which are not so effective for obtaining permanent positions.

"I worked for 6 hours a day as intern, other employees also worked for 8 hours and get paid, I don't get salary but governmental subsidies."

- Interviewee I

Among the labour market measures, such as different courses, work related initiativess, educational measures, work related rehabilitation and consulting are good initiatives for promoting jobs. However, these are only available to unemployed individuals and remain out of reach for the many immigrants who are in a situation of underemployment in Lapland. The new integration program of Rovaniemi 2018 focuses on the dilemmas of labour market integration amongst the immigrant population in the city. The municipality has already started to work on this brand-new integration program. Various aspects of the immigrants' lives, including employment support programs that are available as a part of an on-going project like e.g. OSMA are available, but there is no adequate outreach program to inform immigrants of the vari- ous support possibilities available. According to one interviewee:

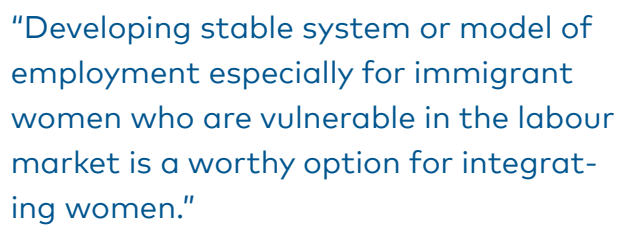

\section{Experiences from Internships}

The challenges that immigrant women face in finding jobs vary from immigrant to immigrant, including their cultural background (Yeasmin, 2017). All immigrants capitalise on their opportunities differently in terms of their skills and approaches to work, which are critical factors in finding a job (Pehkonen, 2006). The educational levels, professional experiences, age, gender and socio-cultural backgrounds of immigrants are distinctive according this study. Some previous studies states that self-esteem and the motivations of immigrant women with respect to gaining access to the labour market is also important (Jamil et al. 2012; Yeasmin 2017). According to the interview, the challenges immigrants face are similar to those faced by immigrants in many welfare countries in Europe. In spite of having academic and professional achievements, they experience difficulties in finding matching jobs (Yeasmin 2017). Sometimes, immigrants reported that they are unable to find an internship place according to their educational background. Some small business sectors in Rovaniemi (like accountancy farms, hair dresser, cosmetology etc.) do not usually offer any internship places for those of foreign backgrounds. According to the employers, their businesses are too small to take an intern. They do not have enough employees to guide the intern during internship, which discourages immigrant women from contributing to the labour market, and in turn create long-term unemployment problems among immigrant women.

Immigrant women also lack information about internship places. They are often not motivated enough to search for an internship for themselves because of e.g. language barriers, limited networking opportunities, as well as other responsibilities related to family and often end up by imitating other women from similar background and their trajectories. As a response to this, there are some recognised employers in Rovaniemi that recruit immigrant interns. 
"I think internship is a good way to learn about working life and style in Finland, but the period of internship is maximum 6 months under the same employer which is really a short period time for learning. Even if, there are some internship offer by the labour office is shorter that six months. I don't thing that really promote enough knowledge about the company and the working manners. I think two years' is good time for learning through internship"

- Interviewee VIII

"I was disappointed when I was rejected for the first time to find an internship place based on my first priority." It was my dream to work in a beauty parlour. Now I have vocational education on that profession, but still having problem to get job."

- Interviewee IV

Connecting potential employers with immigrant women through internships could be the first step to get access to the labour market. Many ongoing projects mentioned earlier are working on this issue. However, in theory, it seems that employers are using immigrant's free working hours through subsidised internship. Employers are doubtful about employing immigrants because of different perspectives and difficulties within the workplace, such as miscommunication because of language barriers, conflicting cultural values, and worries connected to the client's attitudes towards ethnic employees. Most employers do not need further employees, as they are operating small or family business. Immigrant women are also indecisive about applying for positions which fit their education because they doubt their linguistic capabilities and their potential. Competing with other local women, immigrant women are inclined to think that they will always be an employer's second choice.

To some extent, joining an internship may be beneficial for both parties to address their concerns and hesitations. For example, tourism is a seasonal business in Lapland and a big industry who is always in need of employees, but the immigrant group of women who get the opportunity to work in the sector are fluent in English, Japanese, and Chinese mandarin etc., reflecting the tourism base and their country of origin. These seasonal jobs are dominated by students, due to the cheap labour they may provide due to the minimum wage levels in these jobs.

Working within tourism is nonetheless a good arena for gathering local working experiences. Immigrant women, generally those who are refugees, are not involved in the tourism sectors. Some immigrant women also said that internship is a better alternative to doing nothing at all or indeed, being long-term unemployed. It may additionally give immigrant women an opportunity to immerse themselves in the workplace with tasks appropriate to their skills based on their education levels. This opportunity provides immigrant women with better confidence, and they feel empowered. They might feel more self-assured in applying for positions which match their qualifications later on.

Most importantly, internships create networking opportunities for immigrant women and can develop a connection between employer and employees. Immigrants usually lack extended social networks in the host country and making Finnish contacts might be useful for getting information about the local life, as well as labour market. In small municipalities even in Europe, networks are extremely important to establish connections in order to get information and opportunities related to integration. Being able to enter these networks is useful for proper integration, which immigrant women, and refugees in particularly, lack in Rovaniemi.

There are policies, but the policies in place lack a comprehensive and formal structure to implement good practices regarding the unemployment and underemployment of female immigrants. There is a lack of constant information and programs to support immigrant women to achieve their career goals. Opportunities to get information is on a case-by-case basis rather than incorporated into a consistent system. For example, getting information depends on how active the individual is, and the availability of bicultural and bilingual services. Immigrant women often feel a sense of shame, fear and ignorance regarding the available resources, and the decision making thus depends on family responsibilities and their husband, according to the interviewees.

\subsection{Discussion and Conclusion}

This study investigated existing policies and practices which could improve the labour market integration of immigrant women in Rovaniemi, a 


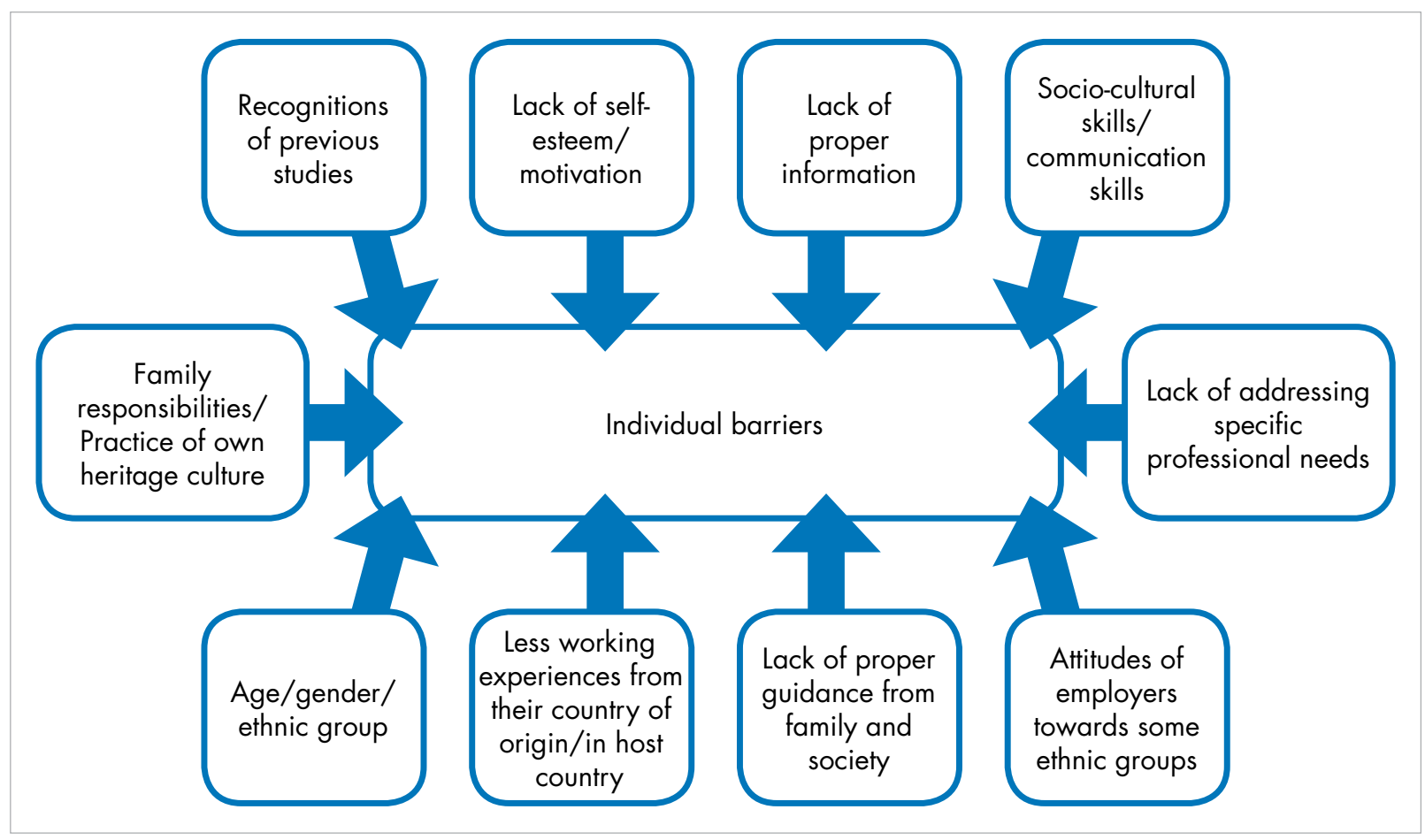

Figure 2: Barriers encountered by immigrant women. Source: own elaboration from the current study

medium-sized northern city. It focused on the experiences of immigrant women in order to get access to the labour market in Northern Finland. According to the previous studies, unemployment and underemployment is most common for immigrant men and women. Furthermore, immigrant women are facing more difficulties than immigrant men.

Unemployment of immigrants in Lapland is common among women, and a job mismatch seems to be a common feature for immigrants in the labour market, but again more so for immigrant women. While addressing this issue in personal interviews with immigrant women and labour market actors, we identified reasons which can keep immigrant women in situations underemployment, as well as potential remedies.

Many barriers have been identified (see figure 2 ) in the current study. The formidable challenges identified are the following:

Both labour market actors and immigrant women acknowledge that language is one of the key elements to be able to communicate and navigate the labour market in Finland. Employers tend to accuse immigrants of lacking the sufficient levels of a professional language standard and that this is the main barrier to entry, although our respondents feel that the attitudes amongst em- ployers towards immigrants is the real issue. Unavailable opportunities for language training is a hindrance for improving the skills, as respondents find that they usually have their own network who speak their own language rather than Finnish. The knowledge of Finnish is important for everyday communication and for building relationships and to acquire a position within the local labour market.

Immigrants who have a resident permit has lot more opportunities available to learn Finnish language, although there is a que. Sooner or later, they will learn Finnish if they are able to find the motivation within themselves. Sometimes it can be hard to attend lessons while there is loyalty toward their husbands, families and their own culture that may hinder their opportunities. Another hindrance is immigrant women underestimation of their language performances and abilities that undermine their confidence and motivation for practicing local language. They are ashamed to practice the language, as they think that they do not speak "perfect Finnish". They make an unreasonable comparison between native speakers and their husband who speaks a bit better than themselves. They experience exaggerated concerns about making errors when speaking and feel anxious, 
"When I was with my husband, my husband handled everything, so I don't need to talk much at that time"

$$
\text { - Interviewee VII }
$$

\footnotetext{
"Many immigrants' women displayed fear of rejection and inappropriateness, when they are with their husband to our services, they don't even try to speak, if we ask any questions to the women: husband starts to answer the question...."

- Interviewee social actor XII
}

However, the situation is reverse among European and highly educated immigrant women. Asian, African and Arabian married women are very much dependent on their husband. Organising language lessons or workshops only for women, which also enhance the self-confidence of immigrant women, may be a welcome addition to traditional language learning classes.

There are no provisions made within the workplace, such as an hour dedicated to language learning during work hours, which might be a good incentive to encourage employees to study Finnish. According to our respondents, they can practice Finnish only during coffee and lunch times during their internships.

Age is also a factor to getting job and acquiring the language. Immigrant women who are older are not motivated to learn the language to the same extent as the younger women, and they also lack working experience from their country of origin. This group of people lack self -esteem and motivation. There are other groups that are highly educated but also lack self-esteem and motivation because of underemployment and non-recognition of their qualifications. According to one of the interviewees, the lack of addressing specific professional needs of the labour market is also demotivating immigrant women, since the availability of jobs in some profession is disappearing in Rovaniemi. It is important to have some policies addressing future job sectors, whilst making immigrant women capable for meeting the future labour market needs by providing necessary suggestion and guidance about vocational education. Similarly, some policies are needed to guide specifically immigrant women who are in need of a specific set of support in the labour market, and to provide sufficient information and guidance to women about labour market and job search processes. Some immigrant women do not get support from their families in job searching, which is has become increasingly digitalised. Some immigrant women are not that advanced in the area of using digital tools and may need special support along with regular supervisory support.

Recent studies identify some recommendation to improve existing policies and practices to make immigrant women capable for working in the local labour market. There is a need to develop the capabilities of labour office personnel at being able to address the needs of immigrant women who are seeking jobs. Not only that, it is also important to monitor all the integration steps of immigrant women so as to identifying the real dilemma, and stress what immigrant women are facing in proper integration processes. For improving their abilities, the services are also needed for recognising their previous qualifications as soon as possible after arriving in Finland. The same integration policies for a large group comprising of a very diverse set of immigrants do not necessarily cover all the problems that immigrants of different ages and gender are facing. Actions on the individual level could be difficult to provide and is also an expensive process, but measures for certain groups of immigrant women or group of women who have certain needs could solve some shortcomings of basic services. Resolving some problems for this group requires a permanent structure that can investigate different life situation of women in different small and medium-sized cities. Not necessarily all immigrant women in Finland are facing similar problems, problems may also vary in different cities. In bigger cities they have different challenges and opportunities than northern small or medium-sized cities. Therefore, the involvement of local government in policy making may identify actions that take better account of the immigrant women's life situations in the local society in Finland. 



\section{Participants and methodology}

Data were gathered through semi-structured indepth interviews with immigrant women, local employment actors, and actors involved in labour market integration of immigrant women. The female participants were all recruited on a voluntary basis as long as they suited the criteria, which were to live in one of the three Arctic cites, to consider oneself an immigrant woman, to have formal education and to be (or have been) in employment that did not reflect their education or had experience difficulties entering the labour market. In addition to the women's labour market experiences in the host country, they were asked about their background, their education, and their migration stories. The names used in this article have been anonymised to preserve confidentiality.

The interviews with were analysed using thematic analysis, identifying themes and patterns within the data (Braun \& Clarke, 2006; Vaismoradi et al., 2013). This method of analysis is aimed at identifying and bringing related concepts from a set of interviews in categories, and to produce descriptive and detailed data within these categories. It is a flexible method whose aim is to understand a phenomenon from the participants' perspective (ibid.).

\footnotetext{
Akureyri

In Iceland, nine immigrant women recollected their employment experiences, and four local employment actors shared their insight on the labourmarket integration of immigrant women. The women came from various backgrounds, their age varied from 25 years old to 58 years old. Three participants were highly educated and held a M.A degree. Four interviews were also conducted with individuals involved in the labour-market integration of immigrant women; one employee from the local job centre, two employers from the hospitality industry and one employee from the municipality discussed their experiences of the labour-market and immigrant women in Northern Iceland.
}

\section{Luleå}

The women interviewd in Lulea came from various backgrounds, both culturally and educationally, and their ages ranged from 24 to 47 years old. Six women with university degrees qualifying for the programme Korta vägen; 2) Two women who either did not qualify for the programme and/or found alternative routes to the labour market, and 3) Two women who stand farther away from the labour market due to a lack of education in their home countries. Approaching the subject from various angles, additional interviews were conducted with three employers of immigrants of different backgrounds and skill levels, as well as a representative from the local Public Employment Agency, the manager of the project Korta vägen, the on-site manager of the initiative Bazar and one of the assistants working at Bazar. For the Luleå case study, 17 interviews were conducted in total.

\section{Rovaniemi}

The women interviewed in Rovaniemi came from various backgrounds. Their age varied from 23 years old to 58 years old. Five women did not have any educational background from their country of origin but have since moving to Rovaniemi achieved formal education at a vocational school. Two interviews were also conducted with individuals involved in projects related to labour-market integration, working directly with immigrant women via civil society organisations. Two employers as well as one employee from the municipality of Rovaniemi discussed their experiences of the labour-market and integration of immigrant women in Northern Finland. 


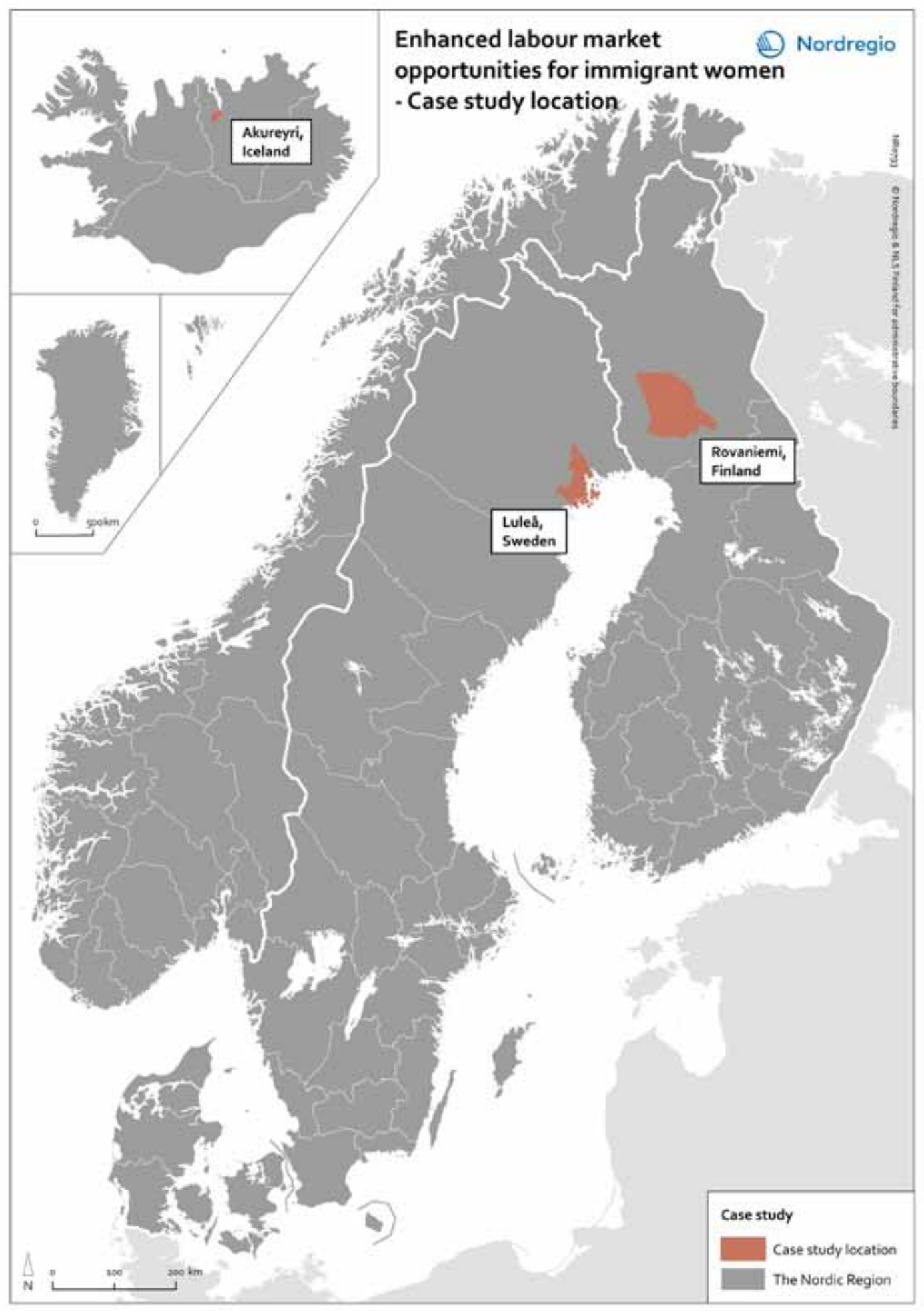

\section{Disclaimer: Limitations of the study}

There are some limitations to this study. The sample size of the interviewees, coupled with the diversity of the groups make it hard to generalise on the matter. The study's scope and time scale also made it hard to go adequately in-depth on some of the topics that surfaced. This includes further interviews with immigrants that do not fit into the programmes examined in this study. This realisation highlighted that there are potentially more indicators that implicates the access to the labour market, in accordance to your education and experience. The study could also have benefitted from in depth interviews with co-workers and employers that do employ few or no immigrants to shed light on attitudes and perceptions in the work place. 


\section{Concluding remarks}

The case studies presented in this working paper provide insight into the process of labour market integration for immigrant women in selected Arctic cities in the Nordics. The key findings are based on observations from the three case studies included in this research and should be considered as motivation for policy makers and integration workers when creating measures and working with integration and inclusion of immigrant women.

The three cities Akureyri in Iceland, Luleå in Sweden and Rovaniemi in Finland are all considered arctic cities, with service centres far away from the capital cities. The cities/towns differ to some extent with regards to e.g. immigration, policies, employment/unemployment rates, size, composition of the labour market and measures in terms of labour market integration. However, immigrant women face challenges in all three cities, in term of transition to the labour market, whether it is job mismatching or entering the labour market in general. Even in Akureyri where unemployment is very low (2.7\%) and in the city of Lulea which is dealing with labour shortage in many sectors, this remains an issue.

The importance of proficiency in the native language was considered highly important in all three case studies and an integral part of labour market integration; these are also skills needed to understand and navigate the local labour market. The importance of native language skills is not only important for improving the chances to gain labour market access, but it is also important for social integration, and full participation in the society. The hindrances for learning the local language were similar across the three cities and can be centred around e.g. access to courses, lack of opportunities to practice the new language, lack of motivation and self-confidence, and time shortage due to work and family obligations.

The access to language learning courses was most limited in Akureyri out of the three cities and described as 'inconsistent' by its participants. The courses are offered on the basis of supply and demand, which can impede or delay mastering the language. The immigrants are thus subjected to the capacity of the language course providers. In the other cities, Lulea and Rovaniemi, where the availability of language courses is more stable there is still room for improvement, which is worth considering when creating the structure for the language courses. Taking this into consideration, it might be worth looking at how one might best combine students to get the best results and create more tailored classes that fits the students' needs and abilities.

The labour market integration programs Korta Vägen and Bazar in Luleå demonstrate how programs better designed for different backgrounds and needs can benefit the language learning progress. Although a certain level of the Swedish skill is needed to partake in Korta Vägen, it was clear that the women with higher education thrived in this course. The women reported that they felt they were not able to maximise their time at SFI, the basic Swedish language course sufficiently, as the groups were very varied in terms of their capabilities, which sometimes slowed down the language learning process. The same was true with the group in the programme Bazar, where the women generally had lower levels of education, and where the language teaching was formatted to fit women that stood far away from the labour market. The improvements were also grounded in creating a safe environment through trust, as an all-women group dealing with similar kinds of challenges.

Motivation and self-esteem were also reported as no less important than vocabulary and grammar, as the language learning abilities increased with the confidence of the women involved. Many of the participants had been undermining their own capabilities and found it hard to practice the new language as a result, since they had not obtained fluency. Creating a safe space for language learning for increased confidence, as well as working on important factors such as motivation and encouragement can thus be important elements in language learning. 
The results may be summed up as the following:

- Organising language courses only for women or groups with similar educational background could improve the language learning process, for better integration onto the labour market and participation in society.

- Organising language courses or workshop also designed to bust the selfconfident and motivate labour market participation

- Arranging provisions within workplaces for language learning during working hours.

Combine language teaching with information about the local labour market and how it works.

\section{Overcoming barriers for integration}

Immigrants are often held responsible for integrating whereas social structures do not get deserved attention. Recognising education and qualifications as soon as possible is important to avoid decommissioning knowledge and skills embodied in the respective immigrant. Limited services for immigrants and/or structural barriers involved in navigating the system and evaluating former experience can inhibit integration. Grand gestures and ambitious policies are no solutions if actions do not follow. Schemes need to be in place to recognise education and qualifications early on to avoid creating large gaps in the career path and pushing the immigrants farther from the labour market. Connecting immigrants and employers through internships has the potential to bridge the gap between these groups. For this to be constructive, a structure needs to be in place to mediate between these entities.

Moreover, immigrants are disadvantaged as they rarely have an extended network in the host society; a network that the native-born commonly use to secure employment. To offset these differences, an internship can help to overcome apprehensions and hesitation for both employers and interns and has the potential to reduce job mismatch. The employer gets an opportunity to consider suitability of the intern as a potential future employee, without the commitment of hiring. The immigrant gets a chance to acclimatise to assignments and work with tasks appropriate to their skills and educational level. Furthermore, the immigrants get the benefit of practicing and developing their new language skills in a workplace, whilst the employer is able evaluate the language skills demands and the possibility to give space for development at the workplace.

Additionally, internships services as links between the immigrants and the local labour market and can partly make up for a lack of extended social network. Different methods can provide immigrants with connections to established networks within the community, not least in smaller communities where networks and word of mouth are salient for securing employment. Korta Vägen in Luleå provides the participants with its employees' networks and the programmes reputation to find internships and establish connections with local employers. Such 'gate openers' can also come from other sources, such as mentors willing to affiliate the immigrant with fellow citizens through their own social networks.

Adapting to a new life in a new society may involve many challenges, such as learning an additional language, entering a new and different labour market, being exposed to different social structures, the frustrations of getting one's education and experiences recognised, and not having functional social or support network. It is also imperative to recognise cultural differences and the potential barriers that individuals might perceive within themselves. Facing several obstacles at the same time can be intimidating and reduce confidence, as noted in the interviews. Empowerment through or alongside programmes and support measures creates an opportunity to ease the transition to the labour market and society in general. Motivation is correspondingly an important factor, especially for women far away from the labour market to help them envision themselves as part of the labour force.

Remote regions in need of people to carry the community into the future have the opportunity to take the matter into their own hands and create policies and measures on the local level to take advantages of the education and experience that immigrant bring along. Losing the valuable skills and knowledge they bring is not only a loss for the individual, but a loss for the host community at large. 


\section{References}

\section{Icelandic Case Study: References}

Braun, V., \& Clarke, V. (2006). Using thematic analysis in psychology. Qualitative Research in Psychology, 3(2). 77-101.

Burdikova, A., Barillé, S., Gísladóttir, S. \& Meckl, M. (2018). Underemployment of immigrant women in Iceland: a case study. Nordicum Mediterraneum 13 (1).

Dofradóttir, A. G., Jónsdóttir G. A. (2010). Matarúthlutanir hjálparstofnana: Könnun á samsetningu hópsins sem páði matarúthlutun [Food-aid from charities: survey on the composition of the group accepting food-aid] 24 November 2010. Reykjavík: Social Science Research Institute, University of Iceland.

Jafnréttistofa (2012). Gender Equality in Iceland. Retrieved from https://www.velferdarraduneyti.is/media/rit-og-skyrslur2012/GenderEquality-in-Iceland.pdf.

Jónsdóttir V., Harðardóttir K. E., Garðarsdóttir R. B. (2009). Innflytjendur á Íslandi [Immigrants in Iceland]. Viðhorfskönnun. Reykjavík: Félagsvísindastofnun Hí \& Fjölmenningarsetur. Júlíusdóttir, M., Skaptadóttir U. D. and A. Karlsdóttir (2013). Gendered migration in turbulent times in Iceland. Norwegian Journal of Geography, 67(5): 266-275.

Júlíusdóttir, M. (2010). People, place and culture in regional policy. Rannsóknir í félagsvísindum XI: stjórnmálafræðideild - ritstýrðar greinar: erindi flutt á ráðstefnu í október 2010: 67-77.

Skaptadóttir U. D. \& Loftsdóttir K. (2016). The tourist and the migrant worker: Different perceptions of mobility in Iceland in RancewSikora, D. Skaptadóttir, U.D. (eds.). Mobility to the edges of Europe: the case of Iceland and Poland: 17-37. Warszawa: Scholar Publishing House.

Skaptadóttir U. D. (2014). What happened to the migrant workers? in Durrenberger, P. \& Pálsson, G. (eds.) Gambling debt: Iceland's rise and fall in the global economy, University of Colorado Press: 175-185.
Vaismoradi, M. ,Turunen, H. \& Bonda, T. (2013). Content analysis and thematic analysis: Implications for conducting a qualitative descriptive study. Nursing and Health Sciences, 15(3): 398-405.

Wojtynska A., Skaptadóttir U. D., Ólafs H. (2011). The Participation of Immigrants in Civil Society and Labour Market in the Economic Recession. Research Project Report. Reykjavík: Faculty of Social and Human Sciences, University of Iceland.

\section{Swedish Case Study: References}

Aure, M. (2013). Highly skilled dependent migrants entering the labour market: Gender and place skill transfer. Geoforum 45, 275-284.

Bevelander P. and Pendakur R. (2014). The labour market integration of refugee and family reunion immigrants: a comparison of outcomes in Canada and Sweden, Journal of Ethnic and Migration Studies, 40:5, pp. 689709 [DOI:10.1080/1369183X.2013.849569]

County Administrative Boards of Sweden. (2016). Integration in Sweden. Website. Available at https://www. informationsverige.se/Engelska/Samhalle/Samhallsorientering/Pages/Den-svenska-integrationspolitiken. aspx. Accessed 31.10.2017.

Fernandes, A.G. (2015) (Dis)Empowering New Immigrants and Refugees Through Their Participation in Introduction Programs in Sweden, Denmark, and Norway, Journal of Immigrant \& Refugee Studies, 13:3, 245-264, DOI: 10.1080/15562948.2015.1045054

Grunfelder, J., Rispling, L., \& Norlén, G. (Eds.) (2018). State of the Nordic Region 2018. Copenhagen: Nordic Council of Ministers.

Hagelund, A. and Kavli, H. C. (2017). Integration. In Greve, B. (Ed.), Handbook of Social Policy Evaluation, (pp. 383-402). Cheltenham, UK: Edward Elgar Publishing.

Harbo, L., Heleniak, T. \& Hildestrand, Å. (2017). From migrants to workers: Regional and local practices on integration of labour migrants and refugees in rural areas in the Nordic countries, Nordregio Working Paper 2017:5, May 2017. 
Heleniak, T. (2018). Migration: The wary welcome of newcomers to the Nordic Region. In Grunfelder, Rispling and Norlén (Eds.), State of the Nordic Region 2018. Nordic Council of Ministers, Denmark.

IFAU. (2017.) Flykting- och anhöringinvandrares etablering på den svenska arbetsmarknaden. Available at: http://www.ifau.se/globalassets/pdf/ se/2017/r-2017-14-etablering-pa-den-svenska-arbetsmarknaden.pdf Accessed 31.10.2017.

Karlsdóttir, A., Sigurjónsdóttir, H.R., Hildestrand, Å. \& Cuadrado, A. (2017). Policies and measures for speeding up labour market integration of refugees in the Nordic region. Nordregio Working Paper 2017:9.

Knocke, W. (2000). Integration or segregation? Immigrant populations facing the labour market in Sweden. Economic and Industrial Democracy, 21(3), 361-380.

Kotyrlo, E. (2014). Labour market outcomes of migrant women in Västerbotten and Norrebotten. The Arctic Yearbook, 2104.

Luleå kommun. (2017). Korta fakta om Luleå och Luleå kommun. Available at: https://www.lulea.se/downl oad/18.58e5fa4715e2fg26ga28ced/1505286187907/ korta\%2ofakta\%20svenska\%202017\%2owebb.pdf. Accessed 25.11.2017.

Luleå. (November, 2015). Kompetensförsörjning 20162018. Available at: https://www.lulea.se/downloa d/18.485f4fob15of7fb1d454770/1447771611658/ Kompetensf\%C3\%B6rs\%C3\%B6rjning\%202016-2018. pdf. Accessed 02.02.2018.

Mats Lindell. (2015). Regional handlingsplan för integration och tillväxt Länsstyrelsen Norrbotten. Länstyrelsen Norrbotten.

Sigurjónsdóttir, H. R., and Norlén, G. (2018). Females and labour market integration. Chapter 8 in Karlsdóttir, A., Norlén, G., Rispling, L. And Randall, L. (Eds.), State of the Nordic Region 2018: Immigration and Integration pp. 6o-64. Nordic Council of Ministers, Denmark. (DOI: 10.6027/NORD2018-001

Statistic Sweden. (2018). Inrikes och utrikes födda efter region, ålder och kön. År 2000 - 2017. Available at: http://www.statistikdatabasen.scb.se/pxweb/ sv/ssd/START BE BE0101 BE0101E/InrUtrF oddaRegAlKon/?rxid=f45fgob6-7345-4877-ba25gb43e6c6e299. Accessed 05.08.2018.

Swedish Government. (2017). Regeringen vill att fler utrikesfödda kvinnor ska komma i arbete. Website. Available at: http://www.regeringen.se/pressmeddelanden/2017/og/regeringen-vill-att-fler-utrikes-foddakvinnor-ska-komma-i-arbetel. Accessed 31.10.2017.
Swedish Public Employment Service (2016) Integration på svensk arbetsmarknad - Ett internationnellt perspektiv. Available at: file://C:/Users/hjordisrut. sigurjons/Downloads/L\% $3 \% \mathrm{~A}_{4}$ s\%2orapporten.pdf. Accessed 31.10.2017.

Swedish Public Employment Service. (2017a). Har vi större problem med nyanlända kvinnors etablering och beror det i så fall på ett systemfel? Working Paper 2017:6.

Swedish Public Employment Service. (2017b). Handlingsplan för att fler utrikesfödda kvinnor ska vara sysselsätta i arbete eller studier, 2017-2018. Arbetsförmedlingens återrapportering 2017.

Västra Götalandsregionen. (2014). Utrikes födda på arbetsmarknaden - Ett kunskapsunderlag om arbetsmarknadsintegrationen i Västra Götaland under 2000 talet. Rapport 2014:5 Regionutvecklingssekretariatet.

Visit Luleå (n.d.) Internationella Kvinnoföreningen Esperanza. Available at: http://visitlulea.se/medlemssidor/i/internationella-kvinnofoer-esperanza/ Accessed: 28.02.2018.

\section{Interviewee contributions}

Luleå Kommun (n.d.) Café BaZar, available: [https://www.lulea.se/utbildning--forskola/vuxenutbildning/sfi/cafe-bazar.html]. Accessed 27.03.2018.

Svensk Kött (n.d.) Vad innebär halalslaktat kött i Sverige? Available: [http://www.svensktkott. se/om-kott/stall-en-fraga/faq-djuromsorg/ vad-innebar-halalslaktat-i-sverige-/]. Accessed 27.03.2018.

\section{Finnish Case Study: References}

Burdikova, A., Barillé, S., Gísladóttir, S. \& Meckl, $M$. (in press). Underemployment of immigrant women in Iceland: a case study. Nordicum Mediterraneum.

Chang, C. \& Holm, G. (2017). Percieved challenges and barriers to employment: The experiences of University educated Taiwanese women in Finland. In Immigrants and The Labour Markets eds.by Elli Heikkilä, 1-245. Turku: Migration Institute. 
Eronen A., Härmälä V., Jauhiainen S., Karikallio H., Karinen R., Kosunen A., Laamanen J-P. \& Lahtinen M. (2014). Maahanmuuttajien työllistyminen: Taustatekijät, työnhaku ja työvoimapalvelut. Työ- ja elinkeinoministeriö, Helsinki.

Eurostat. (2016). Unemployment rates for the population aged 20-64, by place of birth and by sex, 2016. Retrieved from: http://ec.europa. eu/eurostat/statistics-explained/index.php/ File:Unemployment rates for the population aged $20-64$, by place of birth and by sex, 2016 (\%25) MI17.png

FOLO. (2015-2018). Foreign Lounge - project, European social fund. Retrieved from: https://www.ulapland.fi/Suomeksi/Yksikot/ Yhteiskuntatieteiden-tiedekunta/Tutkimus/ LAPPEAn-hanketoiminta/Tutkimushankkeet/ Foreign-Lounge-FOLO

Forsander, A. (2008). Integration through the Nordic welfare state: does work makes you in to a real Finn? In: Bloomberg, H.,Forsander, A.,Kroll, c., Salmeenhaara, P. \& Similä, M.(eds). Sameness and diversity. Finland: Helsinki Research Institute.

Haataja A. \& Kauhanen, M. (2010). Extent and explanations for employer demand for parttime work in the Nordic countries. Helsinki: Labour Institute for Economic Research, Labour Institute for Economic Research Discussion Papers 265.

Haataja, A. (2007). Soviteltu työttömyysetuus. Taustaa ja nykytilanne. Helsinki: Valtion taloudellinen tutkimuskeskus, VATTkeskustelualoitteita 430.

Jaakkola, M. \& Reuter. A. (2007).

Maahanmuuttajanaiset entisen Neuvostoliiton alveelta: Resurssit ja sijoittuminen työmarkkinoille. Tuomas Martikainen \& Marja Tiilikainen (eds.), Maahanmuuttajanaiset: Kotoutuminen, perhe ja työ. Helsinki: Väestöliitto, 335-358.

Jaakola, M. (2009). Maahanmuuttajat suomalaisten näkökulmasta: asennemuutokset 1987-2007. Accessed 19 January 2017. http://www.hel.fi/hel2/Tietokeskus/julkaisut/pdf/O9_02_19_Tutkimus_ Jaakkola.pdf
Kangaspunta, K. (2018). OECD:n arvio Suomen Kotouttamisen onnistumisesta ja koulutuksen uudistuksista (OECD's assessment of the success of Finland's integration and reform of education). National Round Table 6th September 2018, Rovaniemi.

Kraus, A. P. \& Kivisto, P. (2015). The challenge of minority integration: politics and policies in the Nordic nations. Berlin: Deutsche National bibliothek.

Lapland Centre of economic development, transport and the environment. (2017). Ulkomaalaiset Lapissa (Immigrants are in Lapland). Retrieved from: https://www.ely-keskus.fi/ web/ely/ely-lappi-tyomarkkinatilastot;jsessi onid =E5744B699AAOCOA071B17092F56F5D A9?p p id=122 INSTANCE alvevalinta\&p_p lifecycle $=0 \& p \quad p$ state $=$ normal $\& p p$ mode=view \&p r p 564233524 resetCur=true\&p r p 564233524 categoryld=14253

Lapland Centre of economic development, transport and the environment. (2017). Työttömät ja työttömien osuus työvoimasta kunnittain - Lappi (Unemployed and the unemployed share of workforce by municipality - Lapland). Retrieved from: http://www.ely-keskus.fi/ web/ely/lappi-tyottomat-ja-tyottomienosuus-tyovoimasta-kunnittain

Midtbøen, A. H. (2015). Ethnic penalties in western labour markets. Nordic Journal of Migration Research, 5(4), 185-193. DOI: 10.1515/njmr-2015-0022. Retrieved from https://www.degruyter.com/downloadpdf/j/ njmr.2015.5.issue-4/njmr2015 - 0022/njmr2015-0022.pdf.

Migration Integration Policy Index. (2015). "Migration integration index in Finland 2014". Retrieved from http://www.mipex.eu/finland

Ministry of Economic affairs and Employment of Finland. (2016). "Government Integration Programme for 2016-2019 and Government Resolution on a Government Integration Programme." Retrieved from: https://julkaisut. valtioneuvosto.fi/handle/10024/79156

Ministry of Foreign Affairs of Finland (2011). "Finland reports to UN on racism, racial discrimination and intolerance." Accessed 29 June 2016. http://formin.finland.fi/public/default. aspx? contentid $=234723 \&$ contentlan $=2 \& \mathrm{c}$ ulture=en -US 
Mutuku, L. S. (2017). Skill-related underemployment of educated immigrants in Finland. Helsinki: Laurea university of applied science.

OECD. (2018). Finland must focus on integrating migrant women and their children to boost their contribution to the economy and society. Retrieved from http://www.oecd.org/finland/ finland-must-focus-on-integrating-migrantwomen-and-their-children-to-boost-theircontribution-to-the-economy-and-society. htm

Open Society Foundation. (2013). Somalis in Helsinki. Finland: Open Society. Accessed 19 January 2017.

Pehkonen, A. (2006). Immigrants' paths to employment in Finland. Yearbook of Population Research in Finland, 42, 113-128.

Rashid, R. (2005). Immigration journey: a holistic exploration of pre-and post-migration life stories in a sample of Canadian immigrant women. International Journal of Migration, Health and Social Care. Vol. 9 Issue: 4, pp.189202.

Riessman, C. (2008). Narrative methods for the human sciences. London: Sage.

Sarvimäki, M. \& Hämäläinen, K. (2010). Assimilating Immigrants: The Impact of an Integration Program. HECER Discussion Paper 306. Helsinki: Helsinki Centre of Economic Research (HECER).

Sarvimäki, M. (2011). Assimilation to a welfare state: Labor market performance and use of social benefits by immigrants to Finland. The Scandinavian Journal of Economics, 113 (3), 665-688.

Sarvimäki, M. (2015). Labour market integration of refugees in Finland. Retrieved from https:// vatt.fi/documents/2956369/4207575/t185.pdf

Shalla, V. \& Clement, W. (2007). Work in tumultuous times critical perspective. Montreal: Mc Gill-Queen's.

Shimilova, Y., Cai, Y. \& Pekkola, E. (2013). Employability of International graduates educated in Finnish Higher Education Institutions. Accessed 17.08.2016. http://www.helsinki.fi/ urapalvelut/valoasurvey/pubData/source/ VALOA09.pdf

Statistics Finland. (2015). Ulkomaalaiset työelämässä (Immigrants are in labour market). Retrieved from: https://www.stat.fi/tup/ maahanmuutto/art 2015-12-17 003.html
Statistics Finland. (2017). Population. Retrieved from: https://www.stat.fi/tup/suoluk/suoluk vaesto en.html

The Employment office. (n.d.). Unemployment security. Retrieved from: http://www.tepalvelut.fi/te/en/jobseekers/if unemployed/ unemployment security/index.html

Tiilikainen, M. (2008). Menestyvät maahanmuuttajanaiset. Väestöntutkimus- laitos, Katsauksia E 33. Helsinki: Väestöliitto.

Yeasmin, N. (2012). Life as an immigrant in Rovaniemi in Politics of Development in the Barents Region eds. by Tennberg, M. 340-362. Lapland: University press.

Yeasmin, N. (2017). Understanding Economic Integration and the Belongingness of Immigrants in Lapland: An Analysis of Hope and Happiness. In Immigrants and Labor Market: Experiences from Abroad and Finland ed. by Elli Heikkilä. Turku: The Migration Institutte.

Yle. (2010). Major unemployment differences among immigrant groups. Retrieved from: https://yle.fi/uutiset/osasto/news/ major unemployment differences among immigrant groups/6155062 (accessed April, 2018). 



\section{(1I) Nordregio}

P.O. Box 1658

SE-111 86 Stockholm, Sweden

nordregio@nordregio.se

www.nordregio.se

www.norden.org 